\title{
CATALOG OF EARTHQUAKES IN SOUTHERN ALASKA
}

\section{APRIL-JUNE 1978}

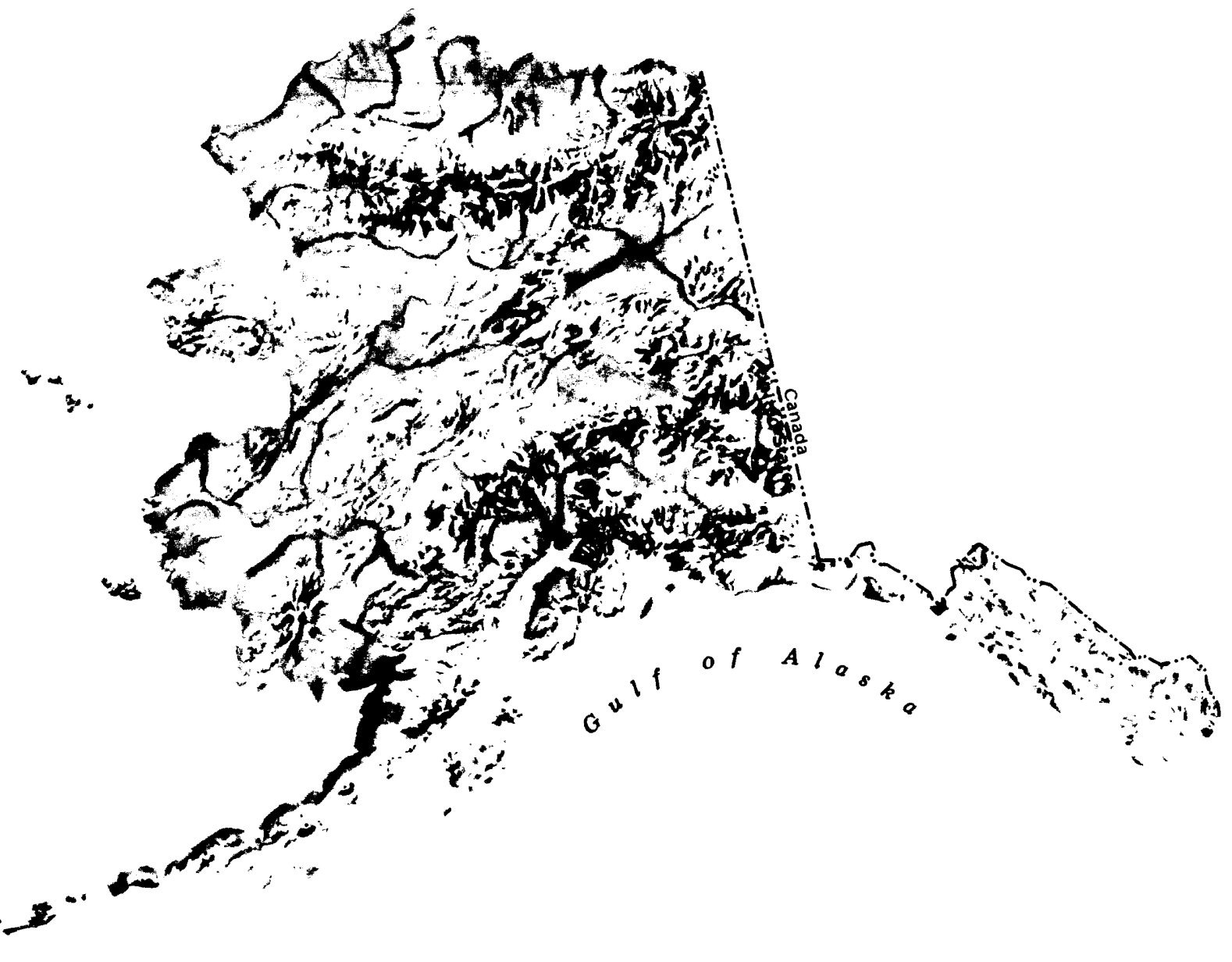

OPEN-FILE REPORT $\mathbf{8 2 - 4 8 8}$

This report (map) is preliminary and has not been reviewed for conformity with

U.S.Geological Survey editorial standards (and stratigraphic nomenclature).

Any use of trade names is for deseriptive purposes only and does not imply endorsement by the U.S.G.S.

Menlo Park, California

1982 
C. D. Stephens, M. C. Astrue, J. R. Pelton, K. A. Fogleman, R. A. Page, J. C. Lahr, M. A. Allan, S. M. Helton

Page

Introduction

Instrumentation

Data Processing

Velocity Models

Magnitude

Analysis of Quality

Discussion of Catalog

Acknowledgments

References

Page

Figure 1 Map showing principal seismograph stations used in

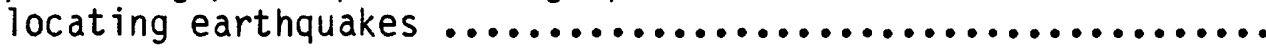

2 Block diagram of the USGS telemetered seismograph system ......

3 System response curves of typical USGS telemetered seismograph stations ............................... 7

4 Picture of a typical seismograph station installation .........

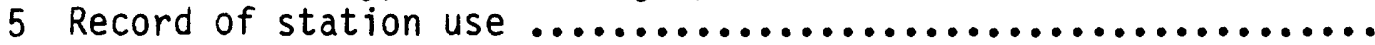

6 Map showing earthquake epicenters reported in the appendix ....

7 Map of epicenters for earthquakes with magnitudes greater

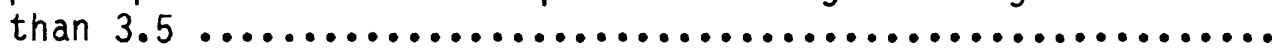

8 Map showing location of cross sections .....................

9 Cross sections showing distribution of earthquake hypocenters

listed in the appendix ............................... 20

10 Magnitude-time distributions for two earthquake clusters ..... 23

\section{TABLES}

Page

Table 1 Station data $\ldots . . . \ldots \ldots \ldots \ldots \ldots \ldots \ldots \ldots \ldots \ldots \ldots \ldots \ldots \ldots \ldots \ldots \ldots$

\section{APPENDICES}

Appendix Southern Alaska earthquakes, second quarter 1978............ 


\section{INTRODUCTION}

The U.S. Geological Survey (USGS) began a regional program of telemetered seismic recording in south-central Alaska in 1971. The principal objectives of this program have been to use data recorded by this network to precisely locate earthquakes in the active seismic zones of southern Alaska, delineate seismically active faults, assess seismic risk, document potential premonitory earthquake phenomena, investigate current tectonic deformation, and study the structure and physical properties of the crust and upper mantle. A task fundamental to all of these goals is the routine cataloging of earthquake parameters for earthquakes located within and adjacent to the seismograph network.

The initial network of 10 stations, seven around cook Inlet and three near Valdez, was installed in 1971. In subsequent summers additions or modifications to the network were made. By the fall of 1973, 26 stations extended from western Cook Inlet to eastern Prince William Sound, and four stations were located to the east between Cordova and Yakutat. A year later 20 additional stations were installed. Thirteen of these were placed along the eastern Gulf of Alaska with support from the National Oceanic and Atmospheric Administration (NOAA) under the Outer Continental She If Environmental Program to investigate the seismicity of the outer continental shelf, a region of interest for oil exploration. During the subsequent years the region covered by the network has remained relatively fixed while effort has been made to improve the instrumentation and installation of the stations in order to make them more reliable.

The locations of the stations of the USGS seismograph network are plotted in Figure 1 and listed in Table 1 along with the additional stations from which readings were obtained. Each USGS station has a single, verticalcomponent seismometer. The stations GLB, PNL, RDT, SKN, and VLZ also have north-south- and east-west-oriented horizontal seismometers.

This earthquake catalog presents origin times, focal coordinates, and magnitudes for 356 shocks occurring in the second quarter of 1978. Readings from a total of 71 stations were used to locate the shocks, including 12 stations operated by the NOAA Alaska Tsunami Warning Center (formerly Palmer Observatory), 14 stations operated by the Geophysical Institute of the University of Alaska (U. of $\left.A_{.}\right)$, one station operated by the National Earthquake Information Service of the U.S. Geological Survey, and two stations operated in southwest Yukon Territory by the Department of Energy, Mines and Resources, Canada.

Earthquakes in south-central Alaska as small as magnitude 3.0 have been routinely located by the National Earthquake Information Service of the USGS and its predecessor since the great Alaska earthquake of 1964 and are published in the reports "Preliminary Determination of Epicenters" (PDE). In contrast, the shocks included in this catalog are as small as magnitude 0.5 and most are smaller than magnitude 3.0. Data for the larger historic earthquakes that occurred in south-central Alaska through 1975 have been tabulated by Meyers (1976). 


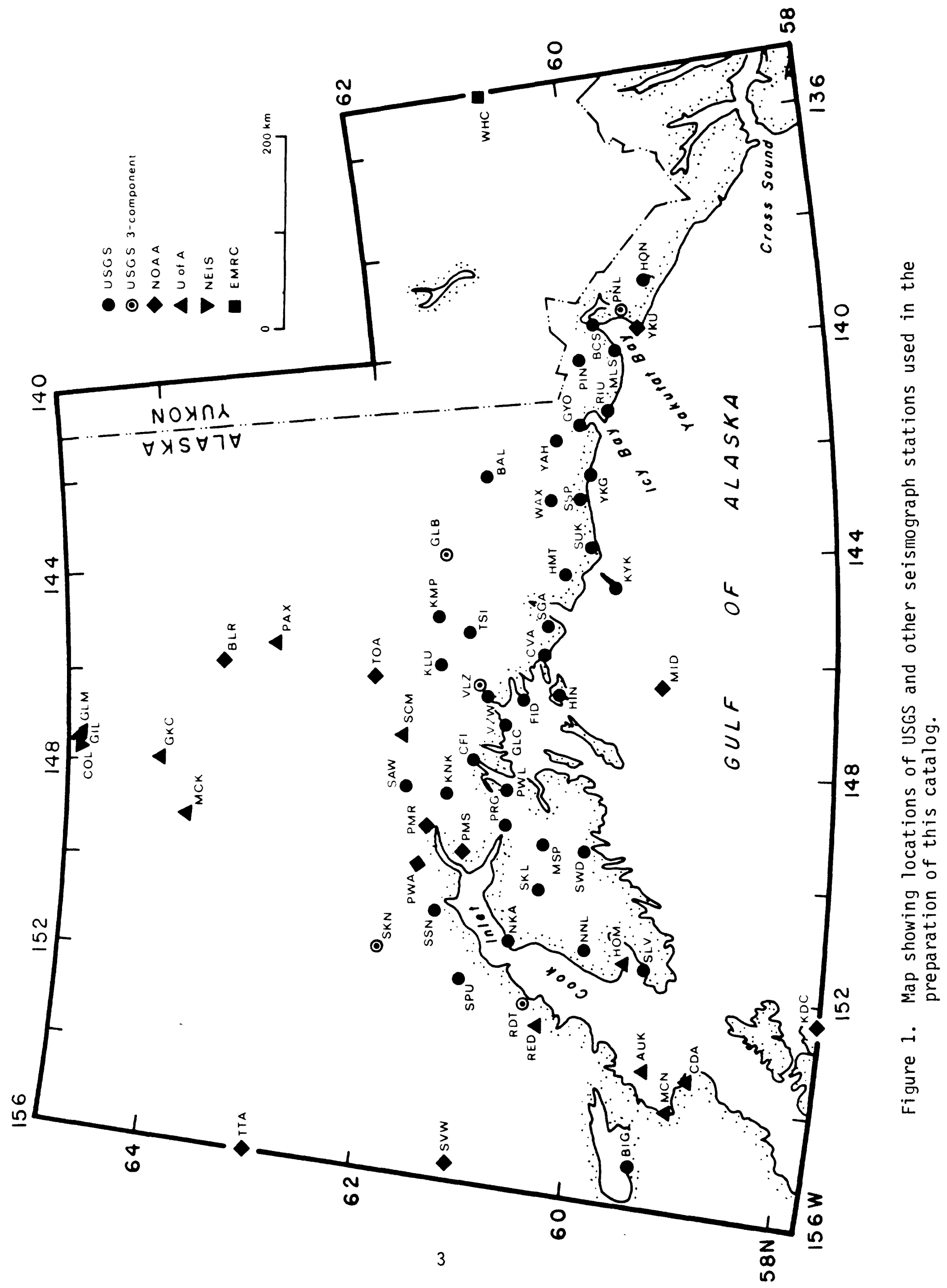




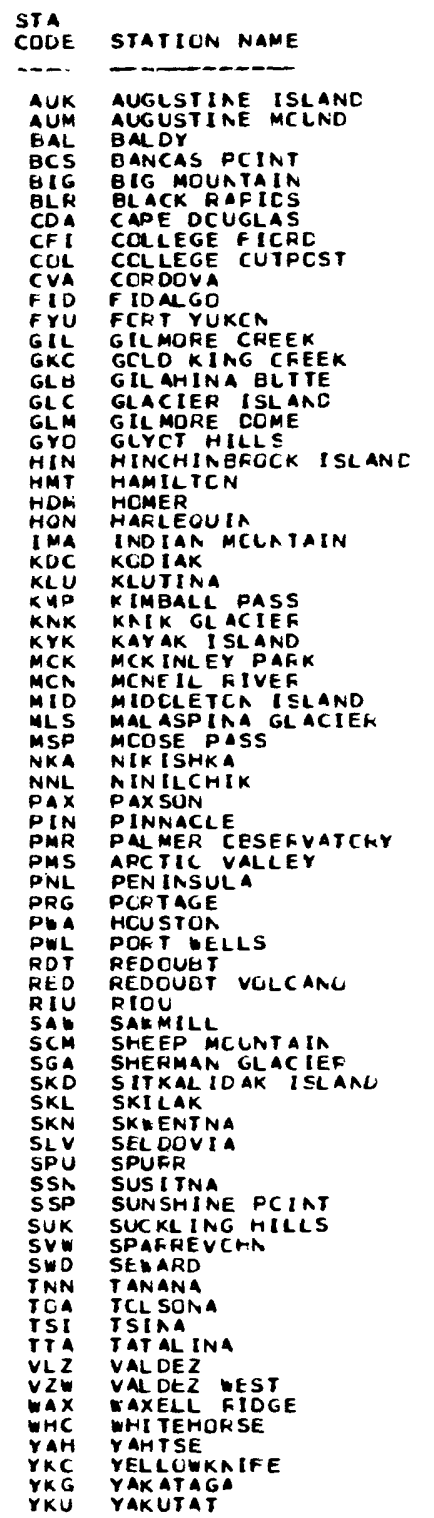

Table 1. Station Data

\begin{tabular}{|c|c|c|c|c|c|c|c|c|c|}
\hline & AGIT & & & & & & & & \\
\hline 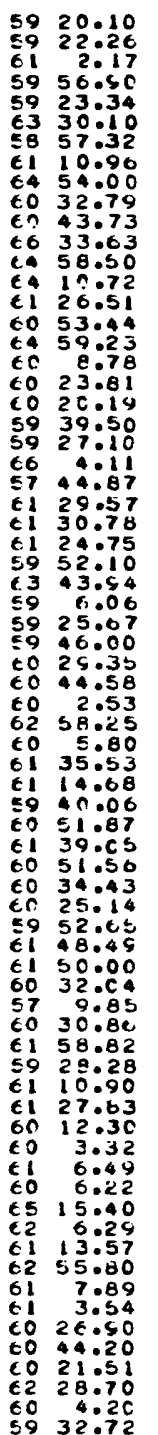 & 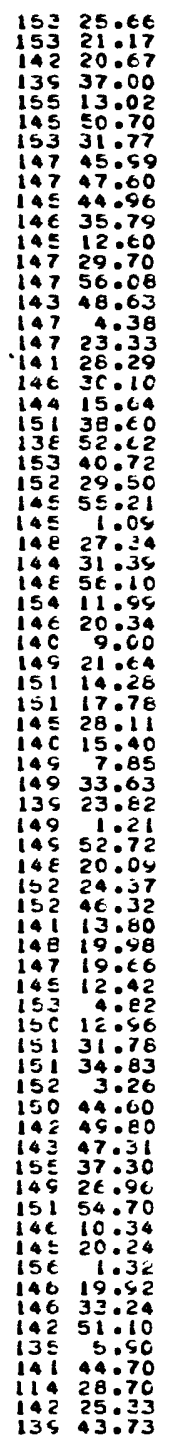 & 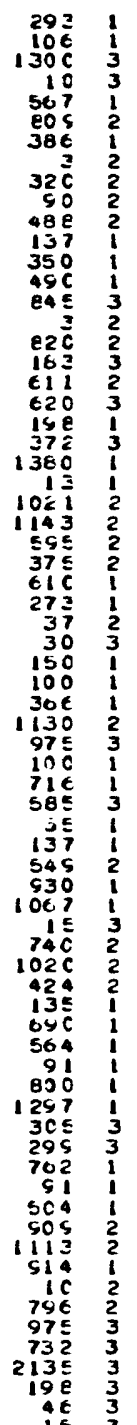 & 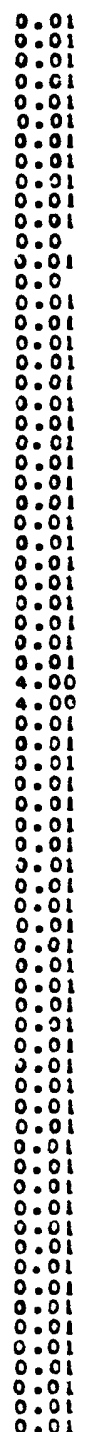 & 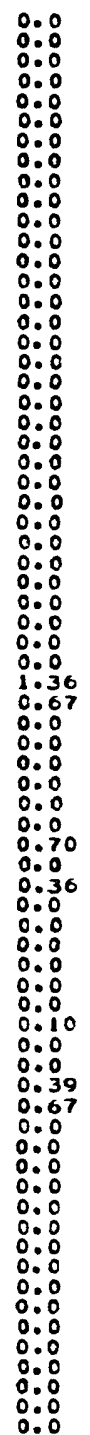 & $\begin{array}{l}0 \\
O\end{array}$ & 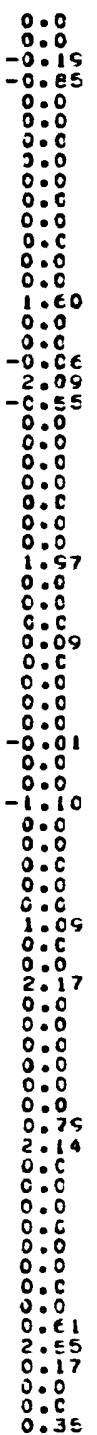 & $\begin{array}{r}-0 \\
0 \\
0 \\
0 \\
-0 \\
0: \\
0 \\
-0 \\
0 \\
0 \\
0: \\
0 \\
0 \\
-0 \\
0 \\
-0 \\
0 \\
0 \\
0 \\
0\end{array}$ & $\begin{array}{r}E C 0 C 0 \\
12000 \\
30000\end{array}$ & \\
\hline
\end{tabular}

This table lists geographic coordinates and other pertinent information for stations used in the preparation of this catalog. P-MOD is the number of the P-wave velocity model assigned to the station (see text), where the numbers 1,2 , and 3 correspond to the western, central and eastern models. $D$ is the thickness of the low-velocity surficial sedimentary layer in kilometers assigned in the calculation of traveltime delays to a given station. DLY1-3 are the station Pphase traveltime delays in seconds. TDLY is the telephone line delay in seconds. The magnification (MAG) of the vertical seismograph component is given at $1 \mathrm{~Hz}$. The institutions (INST) operating the stations other than the USGS Office of Earthquake Studies are the NOAA Alaska Tsunami Warning Center, the Geophysical Institute of the University of Alaska (UOFA), the National Earthquake Information Service (NEIS), and the Department of Energy, Mines and Resources, Canada (EMRC). 


\section{INSTRUMENTATION}

The instrumentation in the USGS seismograph network is illustrated in the block diagram in Figure 2. Data from each seismometer are telemetered to the NOAA Alaska Tsunami Warning Center in Palmer. The standard equipment at each field station includes a vertical seismometer with a natural frequency of $1.0 \mathrm{~Hz}$ (Mark Products, Model L-4), a package consisting of an amplifier and a voltage-controlled oscillator (VCO model NCER 202, or AlVCO, see Rogers and others, 1980), and "air-ce11" storage batteries (McGraw-Edison, Model ST-2-1000). The AlVCO crystal-referenced units have an automatic gain-ranging capability and provide daily information on the gain setting, geophone response, battery voltage, station identification, and temperature. Data are telemetered via a combination of leased telephone circuits (some of which are relayed by satellite and have a $-0.27 \mathrm{sec}$ delay) and VHF (162-174 MHz) radio links. The radio equipment consists of $10 \mathrm{w}$-power transmitters $(100 \mathrm{~mW})$ and receivers adapted from HT-200 Motorola handie-talkie transceivers. Yagi antennae with $9 \mathrm{db}$ directional gain (Scala, Model CAS-150) are used. At some sites where $A C$ power is available, base-station radio receivers (G.E. Model R46AP66B) with greater sensitivity and reliability are used. The central recording facility incorporates a bank of discriminators (NCER 3101 or Develco Model 6203), four $16 \mathrm{~mm}-\mathrm{film}$ multi-channel oscillographs (Teledyne Geotech Develocorder, Model 4000D), a 14-channel analog tape recorder (Bel1 and Howell Model VR3700B), and a time-code generator (Datum, Model 9100).

The principle of operation is as follows: The seismometer translates movement of the ground into an electrical voltage that is fed into the amplifier/vCO unit where the amplified voltage causes the frequency of an audio-band oscillator to fluctuate about its center frequency. The frequency-modulated (FM) tone from the amplifier/VCO unit is carried directly by voice-grade telephone circuit to the recording site or alternately is fed through a VHF radio link onto a telephone circuit. At the recording site the FM seismic signal is demodulated by a discriminator. The demodulated signal, which is simply an amplified form of the initial signal from the seismometer, is recorded photographically on a multichannel oscillograph, together with time marks from a crystal-controlled chronometer. Twenty-four hours of data for 18 stations can be recorded on a single 43-m-long roll of $16-\mathrm{mm} \mathrm{film}$.

Signals from more than one seismograph can be transmitted on a single telephone circuit by employing VCO units with different center frequencies. In the standard configuration there is a $340 \mathrm{~Hz}$ separation between center frequencies and a fixed bandwidth of $250 \mathrm{~Hz}$. Up to eight seismic channels with center frequencies ranging from 680 to $3060 \mathrm{~Hz}$ may be placed on a single voice-grade telephone circuit.

Figure 3 illustrates the response characteristics of the entire seismic system from seismometer to film viewer. The response level at each station is adjusted in steps of 6 decibels so that the ambient seismic noise produces a small deflection of the trace on the film. As a result, the actual response for an individual station may differ from that of the typical station by a factor of 2, 4, 8, etc. The magnification of the typical station is about $6 \times 10^{4}$ at $1 \mathrm{~Hz}$ and $10^{6}$ at $10 \mathrm{~Hz}$. The gain of a station that has an AlvCO 


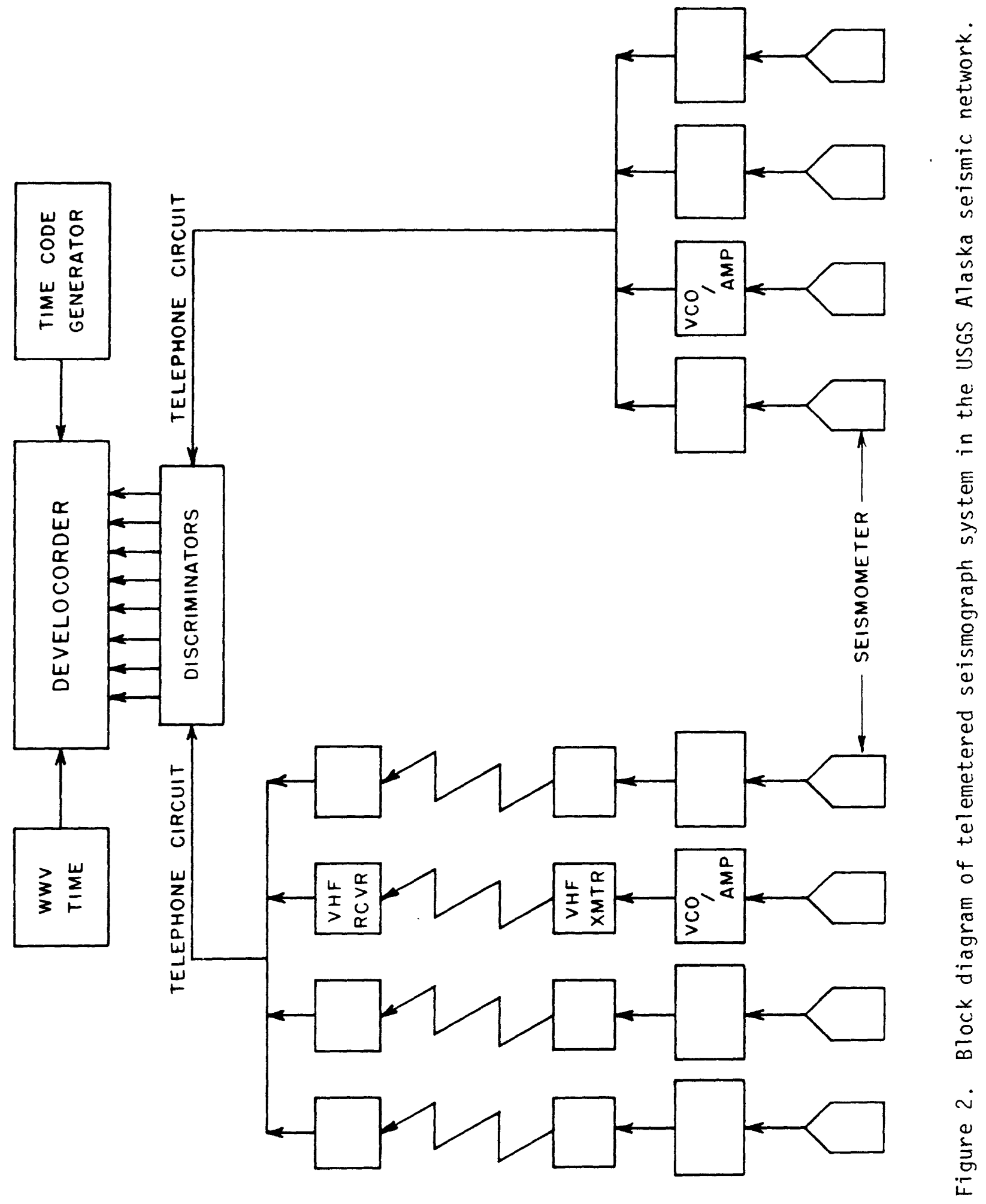




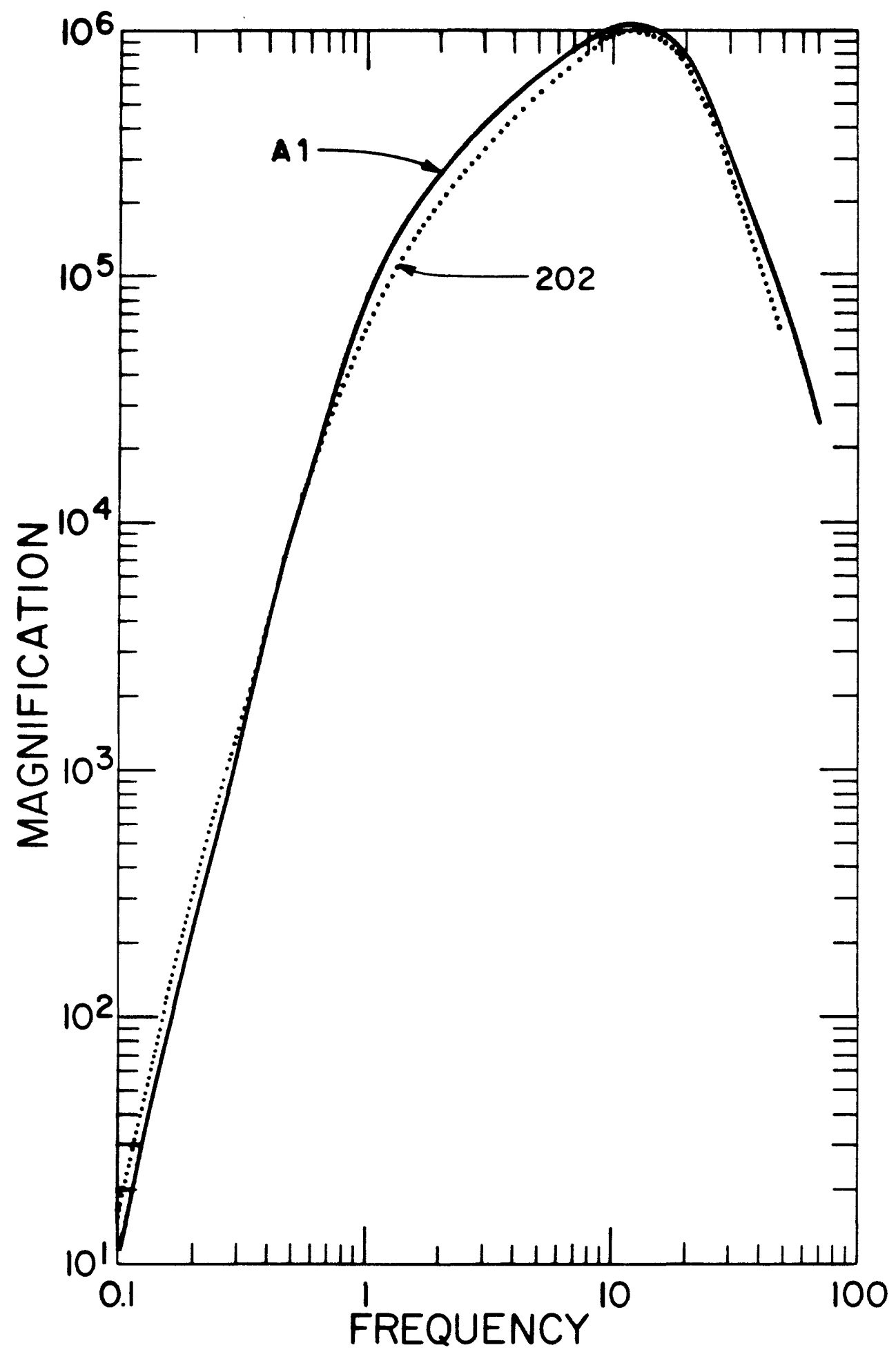

Figure 3. System response curves for typical USGS Alaska seismographs that incorporate the AlVCO unit (solid curve) and the older VCO model NCER 202 unit (dotted curve). 
unit is automatically reduced by a factor of 10 when the fluctuations of the FM signal exceed a preset threshold.

The installation of a typical radio-linked station is shown in Figure 4. Degradation or interruption of data transmission due to inclement weather conditions is a major problem during the winter months. Some indication of the operational reliability of the USGS stations can be inferred from the plot of station use in Figure 5 .

\section{DATA PROCESSING}

The $16-m m$ films (four per day) are mailed weekly from Palmer to Menlo Park where the seismic data are processed by the following multi-step routine:

1. Scanning. The scan film, which has 18 stations distributed throughout the network, is scanned to identify and note times of all seismic events whether of local, regional, or teleseismic origin.

2. Timing. For the "well-recorded" local earthquakes identified in the scanning process, the following data are read from each station: P- and Swave arrival times, direction of first motion, duration of signal in excess of a given threshold amplitude, and period and amplitude of maximum recorded signal. The criterion for choosing earthquakes to be timed is the duration of the signal, which is related to the magnitude. The network is divided into three regions--western, central, and eastern--bounded approximately by longitudes $156^{\circ}$ and $150^{\circ} \mathrm{W}, 150^{\circ}$ and $145^{\circ} \mathrm{W}$, and $145^{\circ}$ and $138^{\circ} \mathrm{W}$, respectively. In the western and central regions, only events with signal durations longer than $80 \mathrm{~s}$ and $20 \mathrm{~s}$, respectively, are timed. In the eastern region, all earthquakes which are recorded by at least three stations and for which at least four clear arrivals can be read are timed. This criterion was established to select from the large number of earthquakes recorded by the network those shocks that are of greatest interest to current research objectives.

For this catalog, timing the seismic phases and measuring the waveform amplitude was accomplished by utilizing a newly-developed system consisting of a computer-based sonic digitizing table with interactive data processing capabilities (Pelton and others, 1982). The system has four main components including (1) an optical film transport unit that can display portions of up to four 16-mm Develocorder films concurrently, (2) a sonic digitizing unit activated by a hand-controlled cursor, (3) a microcomputer that controls the data organization and processing tasks, reduces the digitized data, computes a preliminary hypocenter location and magnitude, and provides an interface with a larger computer for final processing, and (4) a video display for easy monitoring of the current processing sequence, and a printer for permanent recording of each data analysis session. The system is designed to process one earthquake at a time and allow selective remeasurement of any digitized datum. This method is a significant improvement over the standard multi-step processing routine (for example, Lahr and others, 1974) where only one film at a time is viewed and digitized on a non-interactive basis and nearly all subsequent processing is done in a batch mode. 


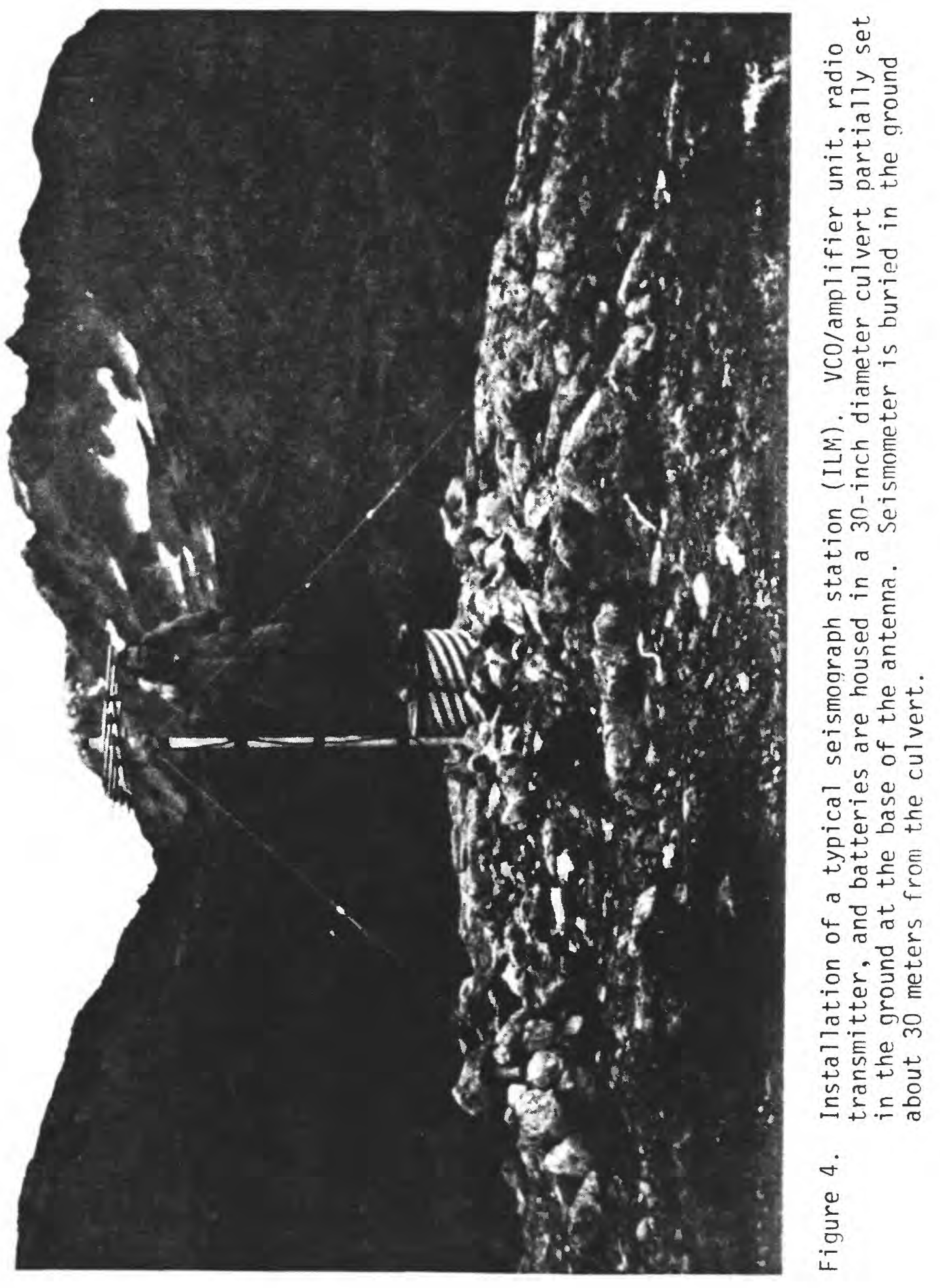




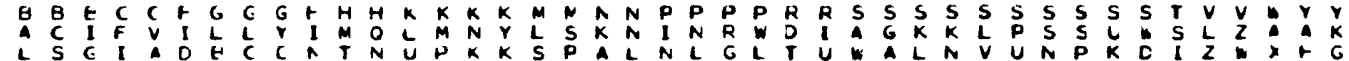
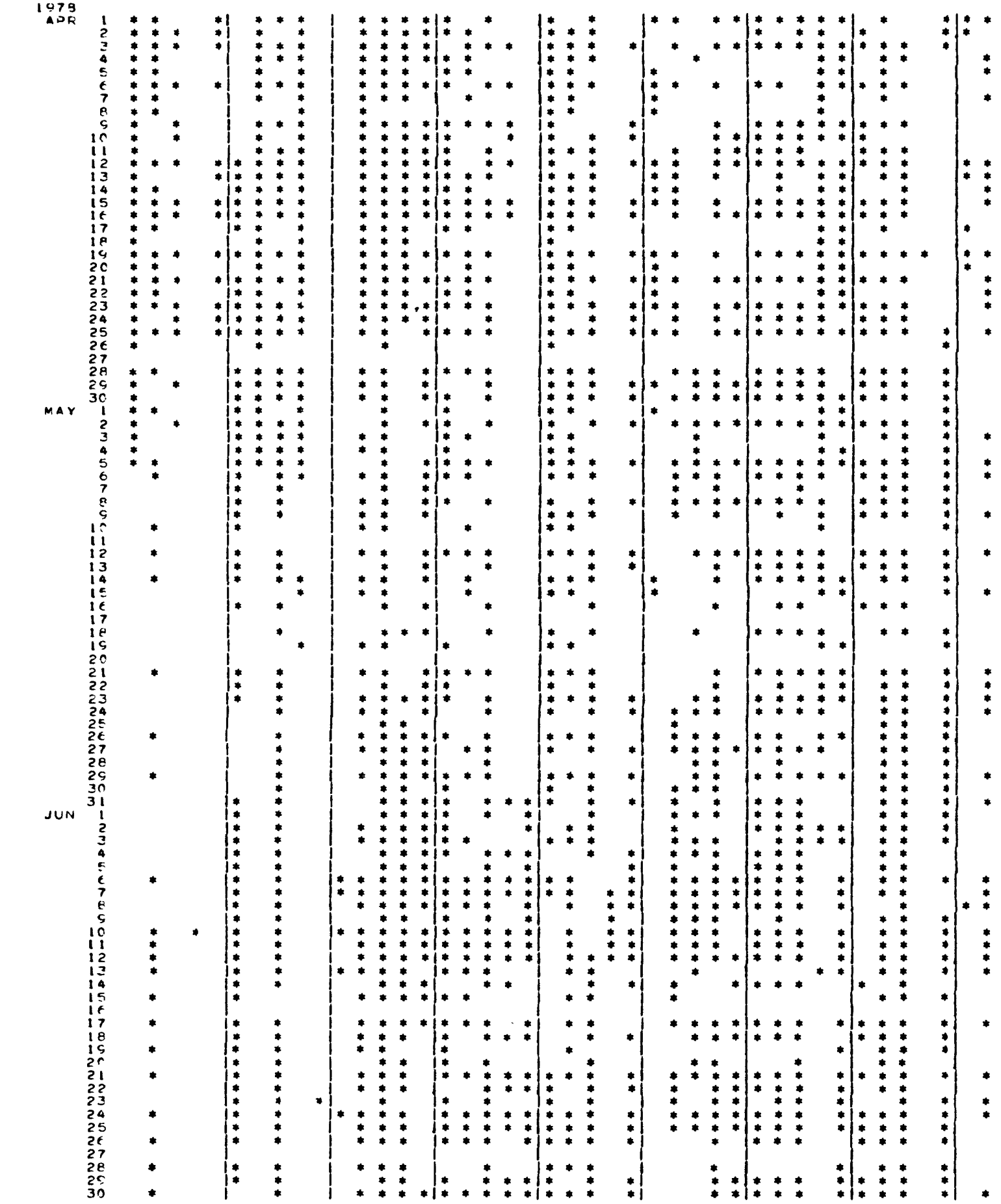

IUTAL NUMEEF LF EVENTS:

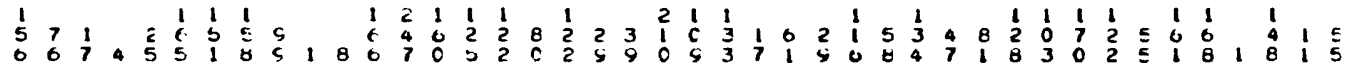

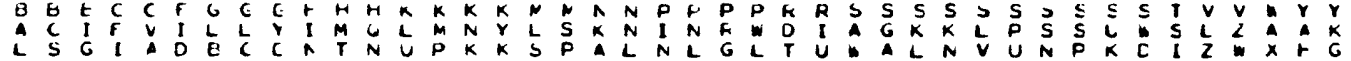

Figure 5a. Record of station operation for USGS stations during the second quarter of 1978. The figure indicated the days on which arrival times were obtained for locating earthquakes. The totals at the bottom indicate the number of events for which each was used. 


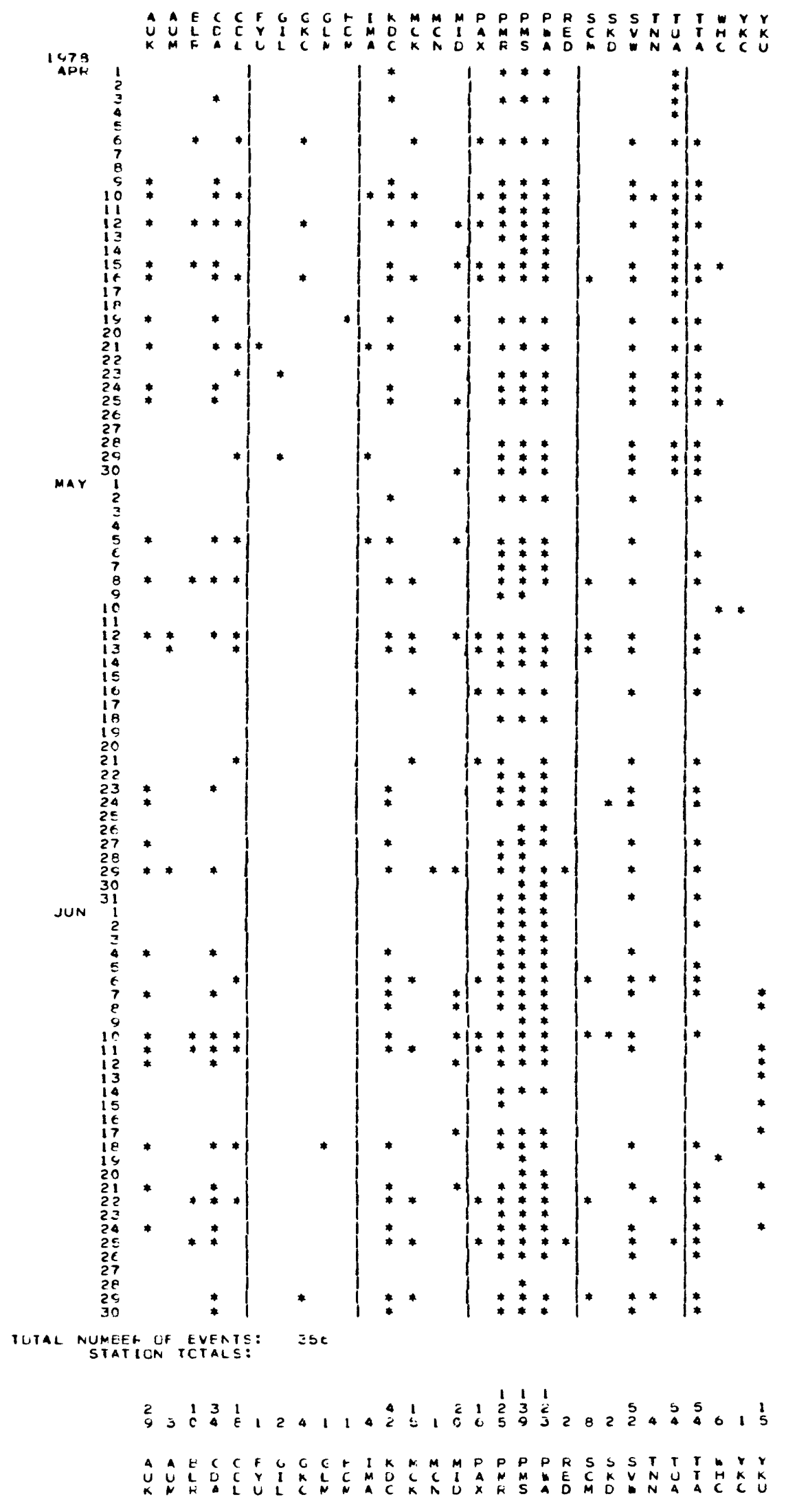

Figure 5b. This information is similar to Figure $5 a$, but represents the frequency with which readings from each of the non-USGS stations were used. 
Final computer processing is done utilizing the computing facilities at the Stanford Linear Accelerator Center and the computer program HYPOELLIPSE (Lahr, 1980). For shocks with a poor distribution of reporting stations, readings from additional stations outside the USGS network are sought and added.

The earthquake locations are based on $P$ and $S$ arrivals. S arrivals are important for determining epicenters of shocks outside the network and depths of events in the Benioff zone beneath the network in cook Inlet. Unfortunately for some large events, $S$ cannot be read at any station because the traces on the film overlap each other or are too faint to follow.

The HYPOELLIPSE computer program determines hypocenters by minimizing differences between observed and computed traveltimes through an iterative least-squares scheme. In many respects the program is similar to HYPOTI (Lee and Lahr, 1972), which has been used in the preparation of catalogs of central California earthquakes since January 1969. An important feature available in HYPOELLIPSE is the calculation of confidence ellipsoids for each hypocenter. The ellipsoids provide valuable insight into the effect of network geometry on possible hypocentral errors.

\section{VELOCITY MODELS}

Our experience with locating earthquakes in southern Alaska suggests that significant lateral variations are present in the velocity structure across the network. Such variations might be expected from the complicated geology and tectonics of the region (e.g., Plafker, 1967). Very little information in the form of direct measurement is available for the velocity structure in southern Alaska. In previous catalogs, only two $P$-wave velocity models consisting of horizontal layers of constant velocity were used to locate the earthquakes (e.g., Stephens, and others, 1979). These velocity models were derived by minimizing the traveltime residuals for selected sets of earthquakes in the Cook Inlet region (Model A of Matumoto and Page, 1969) and near Valdez. The models proved adequate for locating earthquakes as far east as Kayak Island, but earthquakes located farther to the east often had large traveltime residuals at nearby stations. An improved velocity model for the region east of Kayak Island was developed by minimizing the traveltime residuals for a selected set of aftershocks from the $1979 \mathrm{St}$. Elias earthquake that occurred north of Icy Bay (Stephens, and others, 1980b). A significant difference between this model and the earlier ones is that the new model consists of a single layer of linearly increasing velocity over a half-space of constant velocity, whereas the earlier models consist of several horizontal layers of constant velocity.

In the preparation of this catalog, the method of assigning velocity models to calculate theoretical traveltimes to various stations is different from that used in some earlier catalogs. Previously, the velocity model used was determined by the region in which the earthquake occurred and would then be the same for all stations for that event. In the revised procedure, each station always uses the same velocity model, and the model used is determined by the region in which the station is located. Thus, a station in the eastern 
region will use the eastern velocity model to calculate traveltimes from events that occur in the western, central and eastern parts of the network.

West of longitude $148^{\circ} 45^{\prime} \mathrm{W}$ the velocity model used is as follows:

\begin{tabular}{ccc} 
Layer & Depth $(\mathrm{km})$ & Pvelocit \\
\cline { 2 - 3 } 1 & $0-0$ & 2.75 \\
2 & $0-4$ & 5.3 \\
3 & $4-10$ & 5.6 \\
4 & $10-15$ & 6.2 \\
5 & $15-20$ & 6.9 \\
6 & $20-25$ & 7.4 \\
7 & $25-33$ & 7.7 \\
8 & $33-47$ & 7.9 \\
9 & $47-65$ & 8.1 \\
10 & below 65 & 8.3
\end{tabular}

The thickness, $D$, of the first layer is allowed to vary between stations to account for the presence of thick sections of low-velocity sediments beneath the stations NKA and NNL, which are located in the Cook Inlet basin. For these stations $D$ is $4 \mathrm{~km}$. For all other stations $D$ is $0.01 \mathrm{~km}$. It is recognized that a model comprised of uniform horizontal layers may be a poor representation of the actual velocity structure, particularly in the vicinity of a subduction zone (Mitronovas and Isacks, 1971; Jacob, 1972), although such a model does have the advantage of simplifying the computation of traveltimes. In order to determine any bias that might result from this approximation, a set of events in the Benioff zone below cook Inlet was relocated using a ray-tracing program of E. R. Engdahl that incorporates a more realistic, three-dimensional velocity model (Lahr, 1975). Hypocenter shifts, apparently due to the oversimplified flat-layer model, ranged from near zero at a depth of $60 \mathrm{~km}$ to as great as $25 \mathrm{~km}$ at the $160 \mathrm{~km}$ depth. The offsets were oriented in such a way that the dip of the Benioff zone would appear to be too great for locations based on a flat-layered model.

For earthquakes that occur between longitudes $148^{\circ} 45^{\prime} \mathrm{W}$ and $144^{\circ} 30^{\prime} \mathrm{W}$, the velocity model used to locate the events is:

$\begin{array}{ccc}\text { Layer } & \text { Depth }(\mathrm{km}) & \text { P velocity }(\mathrm{km} / \mathrm{s}) \\ 1 & 0.0 & 2.75 \\ 2 & 0.01 & 6.4 \\ 3 & \text { below 39 } & 8.0\end{array}$

East of longitude $144^{\circ} 30^{\prime} \mathrm{W}$ the $\mathrm{P}$-wave velocity of the first layer increases linearly from $5.0 \mathrm{~km} / \mathrm{s}$ at the surface to $7.8 \mathrm{~km} / \mathrm{s}$ at $32 \mathrm{~km}$ depth, while the half-space has a velocity of $8.2 \mathrm{~km} / \mathrm{s}$.

P-phase traveltime delays are applied to stations in the network that have consistent and large residuals for the locations of large groups of earthquakes. Each station has three delays (DLY1, DLY2, and DLY3 of Table 1) 
assigned to it that correspond to the western, central, and eastern regions covered by the network. The particular delay that is used to locate an earthquake is determined by the region in which the earthquake occurs. For example, a station near Icy Bay that is used to locate an earthquake beneath Cook Inlet (western region) will be assigned a delay DLYI, but the same station will use DLY3 to locate an earthquake that occurs beneath Icy Bay (eastern region). Additional delays are applied at several stations to correct for a satellite link in the relay of the signal. S-phase delays are determined by multiplying the $\mathrm{P}$-delay by 1.78 , the $\mathrm{P}$ to $\mathrm{S}$ velocity ratio.

The initial trial depths for earthquakes which occur in the western, central, and eastern parts of the network are 75,30 , and $15 \mathrm{~km}$, respectively, and reflect a progressive decrease in the range of depths of earthquakes from west to east.

\section{MAGNITUDE}

Magnitudes are determined from either the signal duration or the maximum trace amplitude. Eaton and others (1970) approximate the Richter local magnitude, which depends on maximum trace amplitudes recorded on standard horizontal Wood-Anderson torsion seismographs, by an amplitude magnitude based on maximum trace amplitudes recorded on high-gain, highfrequency vertical seismographs such as those operated in the Alaskan network. The amplitude magnitude XMAG used in this catalog is based on the work of Eaton and his co-workers and is given by the expression (Lee and Lahr, 1972)

$$
X M A G=\log _{10} A-B_{1}+B_{2} \log _{10} D^{2}
$$

where $A$ is the equivalent maximum trace amplitude in millimeters on a standard Wood-Anderson seismograph, $D$ is the hypocentral distance in kilometers, and $B_{1}$ and $B_{2}$ are constants. Differences in the frequency response of the two seismograph systems are accounted for in $A$. It is assumed, however, that there is no systematic difference between the maximum horizontal ground motion and the maximum vertical motion. The terms $-B_{1}+B_{2} \log _{10} D^{2}$ approximate Richter's - $\log A_{0}$ function (Richter, 1958, P. 342), which expresses the trace amplitude for an earthquake of magnitude zero as a function of epicentral distance.

For small, shallow earthquakes in central California, Lee and others (1972) express the duration magnitude FMAG at a given station by the relation

$$
\text { FMAG }=-0.87+2.00 \log _{10} T+0.0035 \mathrm{DEL}
$$

where $T$ is the signal duration in seconds from the $P$-wave onset to the point where the peak-to-peak trace amplitude on the Geotech Model $6585 \mathrm{film}$ viewer falls below $1 \mathrm{~cm}$ and DEL is the epicentral distance in kilometers.

Comparison of XMAG and FMAG estimates from equations (1) and (2) for 77 Alaskan shocks in the depth range 0 to $150 \mathrm{~km}$ and in the magnitude range 1.5 to 3.5 reveals a systematic linear decrease of FMAG relative to XMAG with 
increasing focal depth. To remove this discrepancy, a linear dependence on depth is added to the expression for FMAG as follows:

$$
\text { FMAG }=-1.15+2.00 \log _{10} T+0.007 \mathrm{Z}+0.0035 \mathrm{DEL}
$$

where $Z$ is the focal depth in kilometers.

The magnitude preferentially assigned to each earthquake in this catalog is the FMAG estimate. The XMAG value is used only where no FMAG can be determined.

\section{ANALYSIS OF QUALITY}

Two types of errors enter into the determination of hypocenters: systematic errors limiting the accuracy of hypocenters and random errors limiting the precision. Systematic errors arise from an incorrect velocity model, misidentification of phases, or systematic timing errors and can be evaluated through controlled experiments such as locating the coordinates of a known explosion. Random errors result from random timing errors and are estimated for each earthquake through the use of standard statistical techniques.

For each earthquake, HYPOELLIPSE calculates the lengths and orientations of the principal axes of the joint confidence ellipsoid. The one-standarddeviation confidence ellipsoid describes the region of space within which one is 68 percent confident that the hypocenter lies, assuming that the only source of error is random reading error. The ellipsoid is a function of the station geometry for each individual event, the velocity model assumed and the standard deviation of the random reading error. The standard deviation determined from repeated readings of the same phases by four seismologists is as small as 0.01 to $0.02 \mathrm{~s}$ for the most impulsive arrivals and as large as 0.10 to $0.20 \mathrm{~s}$ for emergent arrivals. The confidence ellipsoids are computed for a standard deviation of $0.16 \mathrm{~s}$ and therefore likely overestimate the 68 percent confidence regions. The standard deviation of the residuals for an individual solution is not used to calculate the confidence ellipsoid because it contains information not only about random reading errors but also about the incompatibility of the velocity model to the data. Thus, the confidence ellipsoid is a measure of the precision of the hypocentral solution. In a few extreme cases the value calculated for one of the ellipsoid axes becomes very large corresponding to a spatial direction with very great uncertainty. In these cases an upperbound length of $25 \mathrm{~km}$ is tabulated.

To fully evaluate the quality of a hypocenter one must consider both the confidence ellipsoid and the root mean square (RMS) residual for the solution. The RMS residual reflects both systematic and random errors, but the random errors are typically much smaller. Hence the RMS residual is primarily a measure of the incompatibility of the velocity model, misinterpretation of phases, and systematic timing errors. Interpretation of the RMS residual may depend upon the location of the earthquake. In areas where the velocity model is incompatible with the real earth, RMS residuals could be large and reflect the incompatibility; alternatively, the RMS residuals could be small and not reflect the error in a bad hypocenter. Where 


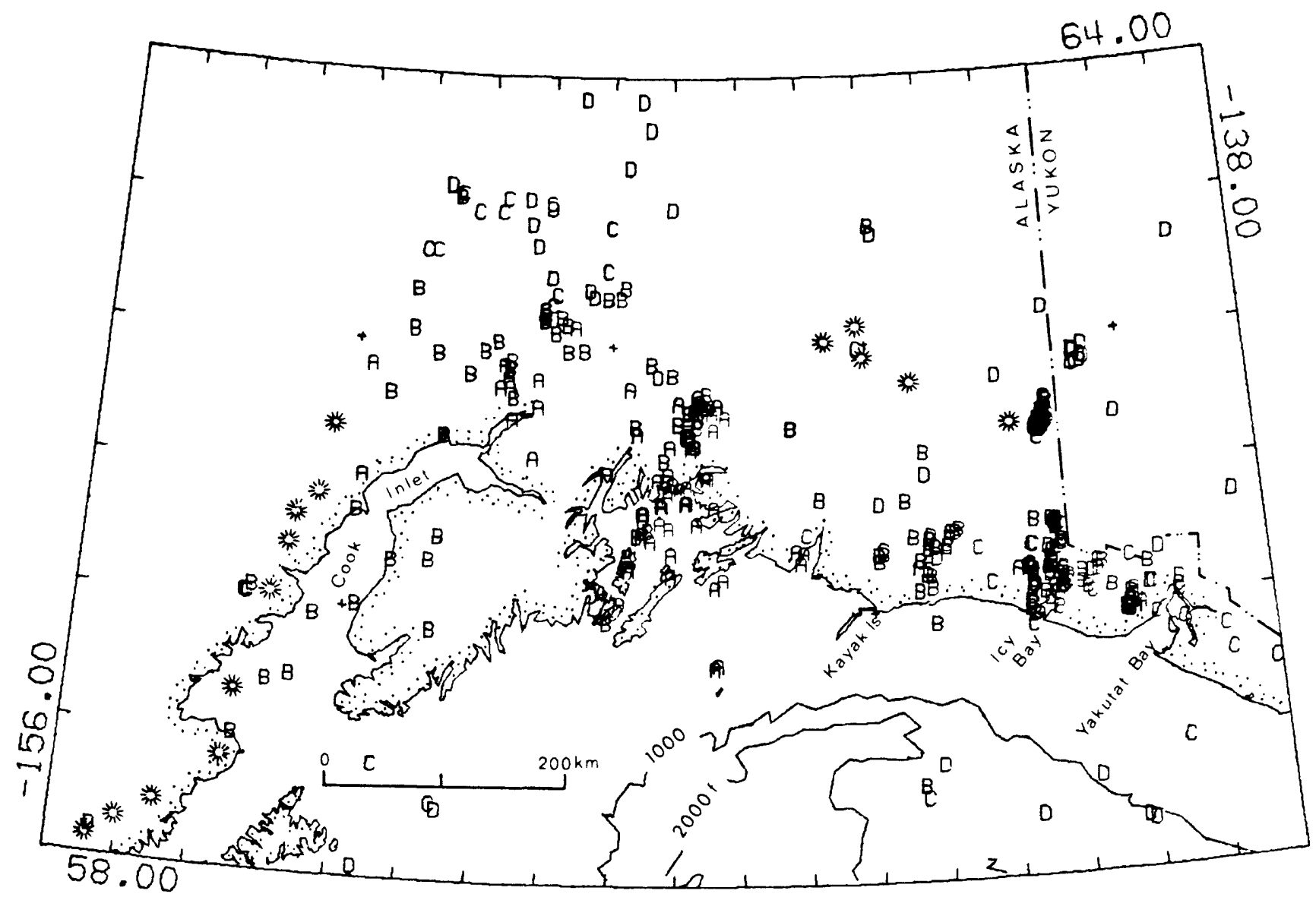

Figure 5. Map of earthquake epicenters for the period April - June, 1978. Earthquakes are plotted with a symbol that represents the quality of the location (see Appendix), with $A$ and $B$ representing better quality. Quaternary volcanoes (after King, 1959) are indicated by stars. 


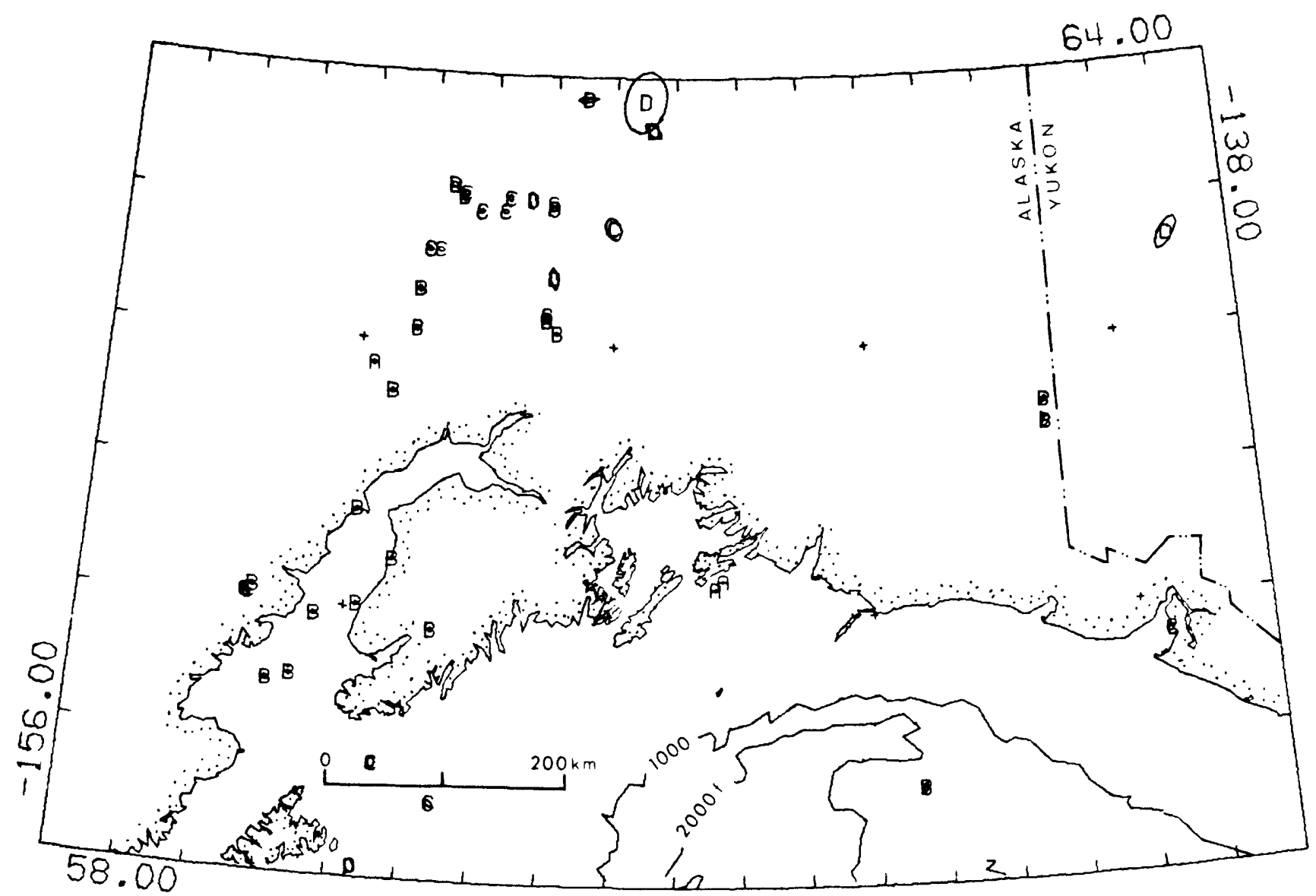

Figure 7. Map showing the epicenters of earthquakes from Figure 5 that have magnitudes of 3.5 and larger. The corresponding projections of the one-standard-deviation ellipsoids onto the surface are also plotted. 
the velocity model is compatible, however, a large RMS residual would indicate probable misreadings of phases.

Other parameters provided by HYPOELLIPSE that are useful in evaluating the quality of a hypocentral solution are: GAP, the largest azimuthal separation between stations measured from the epicenter; D3, the epicentral distance of the third closest station; NP, the number of $P$ arrivals used in the solution; and NS, the number of $S$ arrivals used in the solution. If GAP exceeds $180^{\circ}$, the earthquake lies outside the network of available stations and the solution is generally less reliable than for events occurring inside the network.

\section{DISCUSSION OF CATALOG}

Origin times, focal coordinates, magnitudes and related parameters for 356 earthquakes from April-June 1978 are listed in the Appendix. Epicenters for these shocks are plotted in Figure 6. In Figure 7, only the earthquakes with magnitudes greater than 3.5 are plotted. Vertical sections showing the depth distribution of all of the shocks are presented in Figures 8 and 9.

We estimate that this catalog is reasonably complete for shocks larger than magnitude 3.5 in the western, 2.5 in the central, and 2.0 in the eastern regions of the area covered by the network. The minimum magnitude of the listed earthquakes ranges from 0.5 for shocks at depths of $30 \mathrm{~km}$ or shallower to 2.3 for shocks deeper than $100 \mathrm{~km}$.

The precision of the hypocenters or the relative accuracy of the locations of neighboring events is represented by the confidence ellipsoids. The precision of epicenters, expressed in terms of the maximum axes of the projected one-standard-deviation confidence ellipsoids (ERH), averages 7.3, 3.0 , and $3.7 \mathrm{~km}$, respectively, in the eastern, central, and western parts of the network. Similarly, the precision of focal depth (ERZ) averages about $7.0,4.7$, and $6.7 \mathrm{~km}$, respectively. The variation in the precision of hypocenter determination across the network is strongly influenced by differences in the station coverage in the different regions.

The absolute accuracy of the earthquake locations is difficult to evaluate in the absence of known explosions. Hypocenter biases equal to and larger than the dimensions of the confidence ellipsoids are not unlikely from the oversimplified velocity model assumed in the preparation of this catalog.

The distribution of seismicity throughout the network does not vary markedly from that described for previous and later quarters (for example, Stephens and others, 1980a; Stephens and others, 1979; Fogleman, and others, 1978; Lahr, and others, 1974). A well-defined Benioff zone dips to the northwest beneath the Cook Inlet region (Figure 9, sections G-J). The depth to the top of this zone varies from about $50 \mathrm{~km}$ beneath the western Kenai Peninsula to about $115 \mathrm{~km}$ beneath the active volcanoes west of cook Inlet. The dip of the Benioff zone appears to increase from northeast to southwest, but the depth to the seismic zone beneath the active volcanoes--Augustine, Iliamna, Redoubt, and Spurr--is nearly constant at about $115 \mathrm{~km}$. 


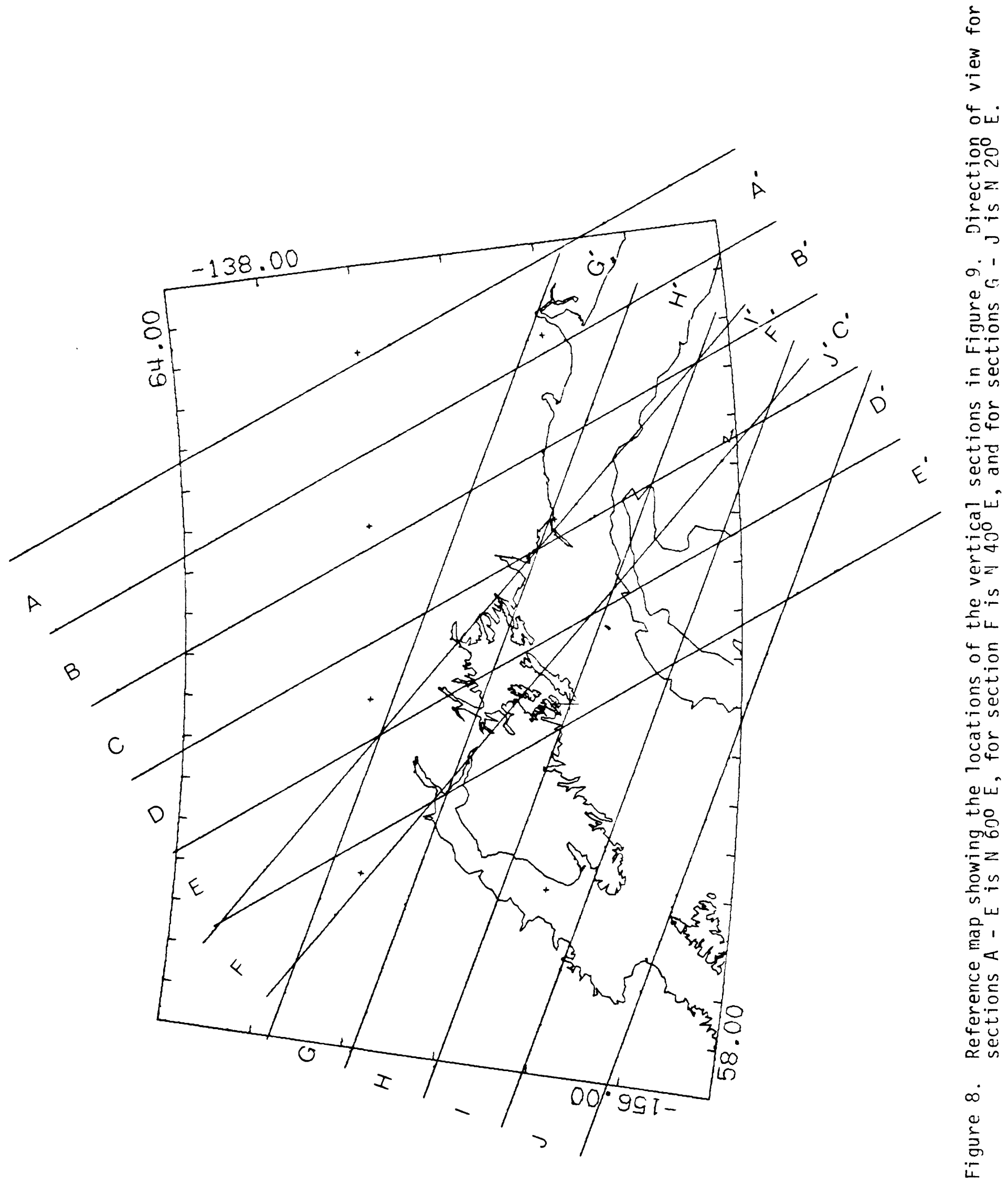



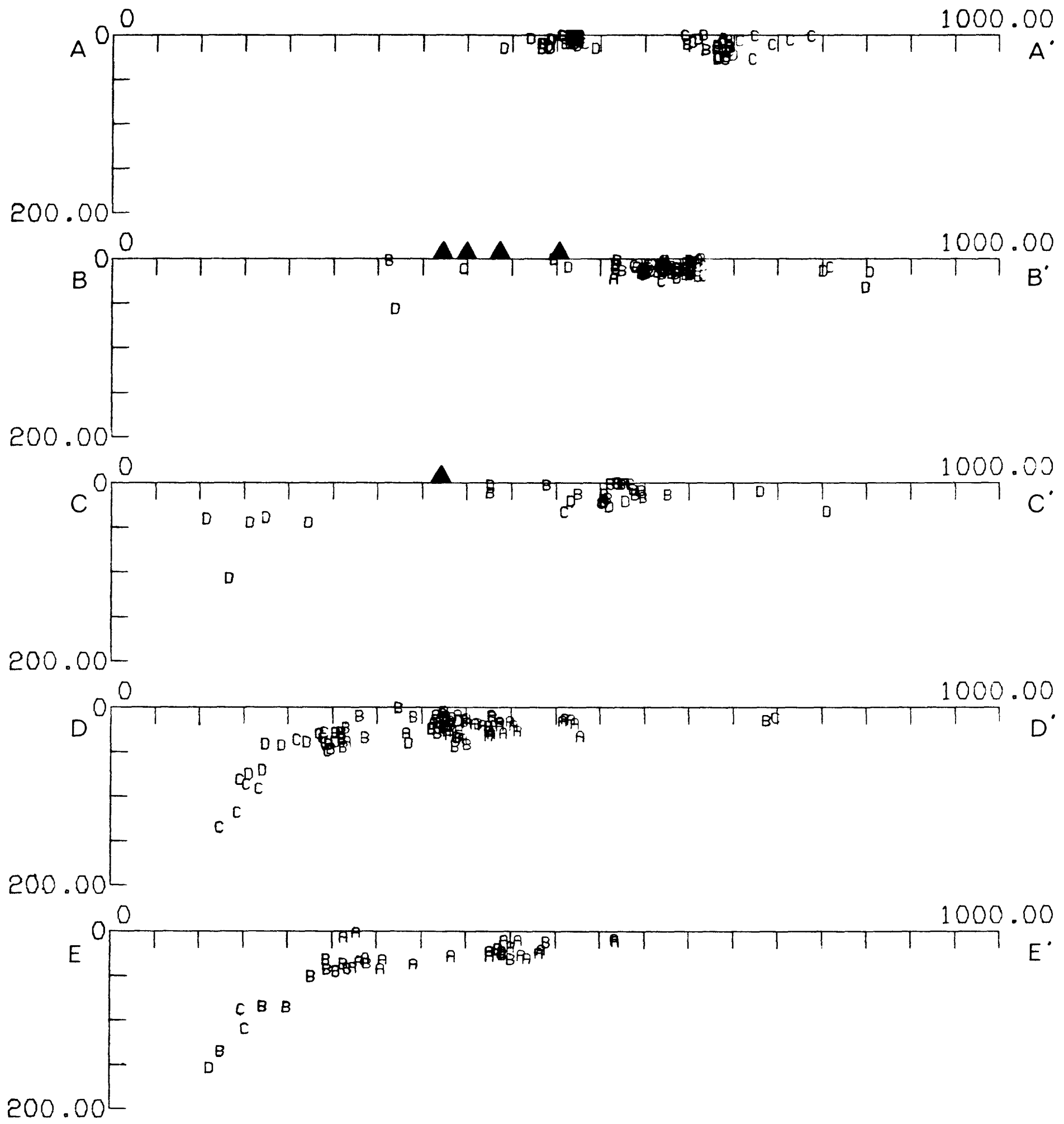

Figure 9 Vertical sections of hypocenters for the areas indicated in Figure 8. Quaternary volcanoes are plotted as triangles at zero depth. All distances are in kilometers. No vertical exaggeration. 


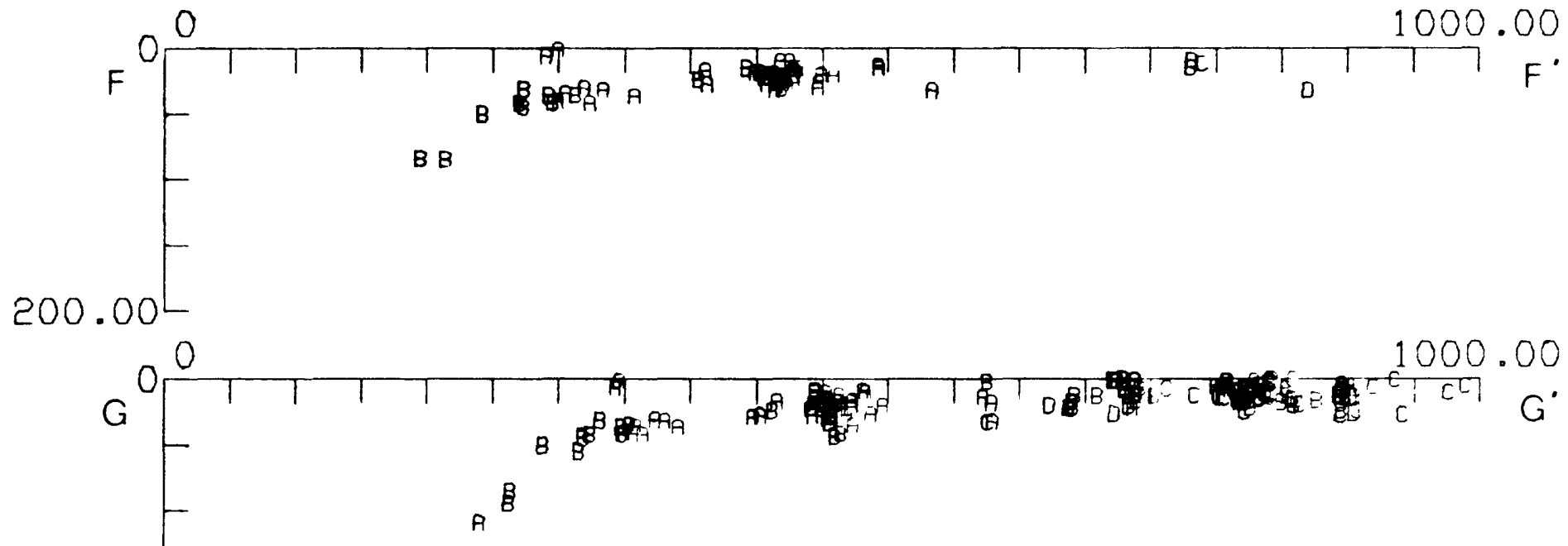

200.00
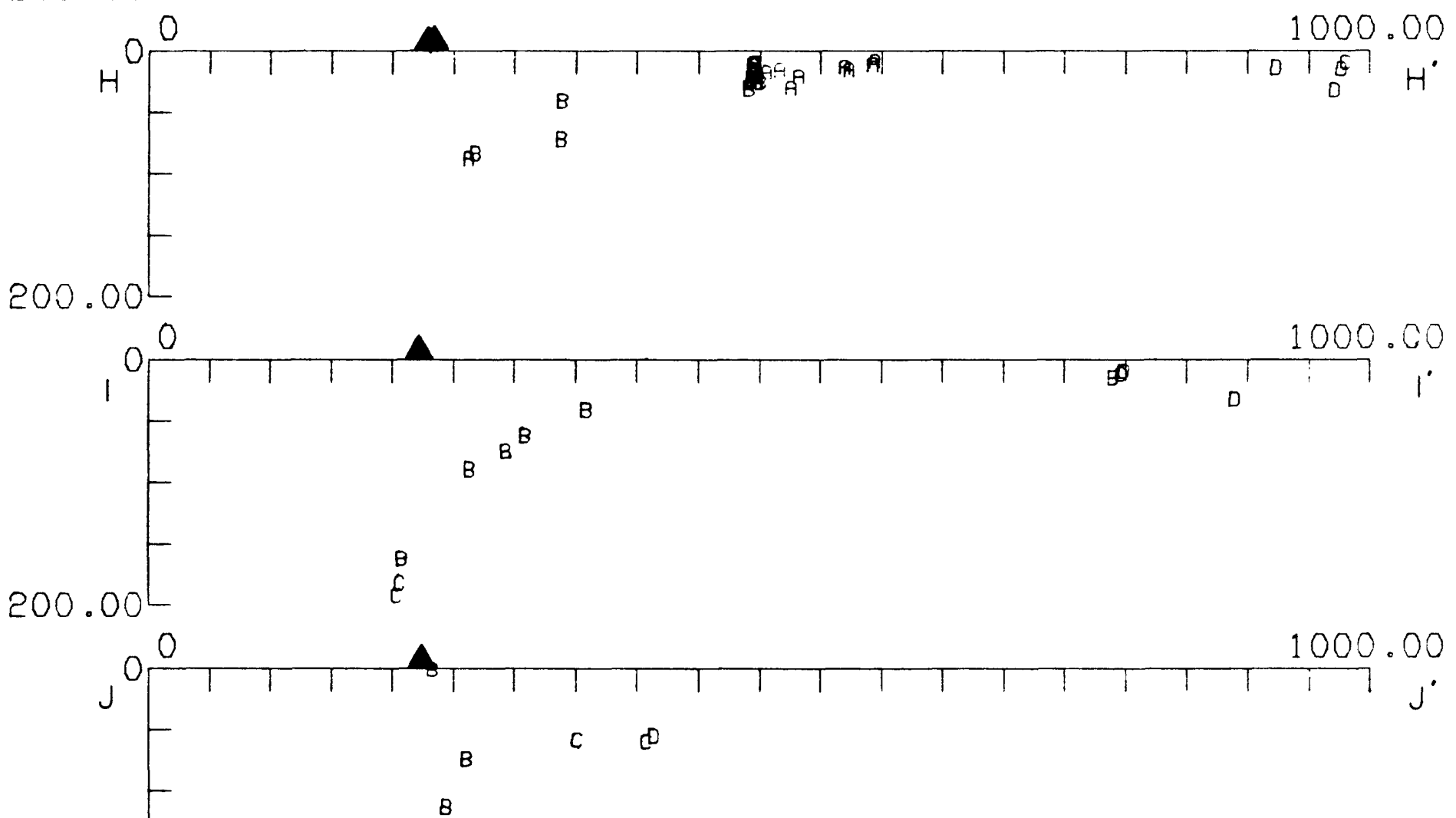

$200.00^{-}$

Figure 9 (continued). 
All of the seismic activity in the southern part of the network east of longitude $146^{\circ} \mathrm{W}$ occurs at depths less than about $35 \mathrm{~km}$. The number of larger magnitude earthquakes which occur in the east is considerably smaller than that in the western part of the network (Figure 7). Most of the seismic activity in the eastern part of the network appears to be concentrated beneath Icy Bay and near Waxell Ridge northeast of Kayak Island.

One notable feature in the seismicity during this quarter is a prominent cluster of events centered near $61^{\circ} 20^{\prime} \mathrm{N}, 141^{\circ} 15^{\prime} \mathrm{W}$, immediately south of the junction between the Totshunda and Duke River faults. A second, less prominent cluster is located about $60 \mathrm{~km}$ northeast of the first near the Denali fault. Poor station distribution and uncertainty in the velocity structure contribute to poor locations for these events and preclude making a clear association of the seismicity with particular faults; the apparent SSW-NNE trend of the main cluster also may be a result of mislocation errors. Although earthquakes continually occur in these areas, the interesting aspect of the clusters is that they occurred during relatively short periods of time in April (Figure 10). Only one of the located earthquakes in each group did not occur during April. Both of these later events, which were among the largest magnitude events in each cluster, did not occur until June. Within the swarm-like character of the main cluster are what appear to be several minor mainshock-aftershock sequences.

Nineteen earthquakes listed in the catalog are located outside of the map area of Figure 6 . Of these events, the largest one had a coda-duration magnitude of $6.7\left(6.0 \mathrm{mb}_{\mathrm{b}}, 6.6 \mathrm{Ms}_{\mathrm{s}}\right)$ and occurred at 03:42 on April 12 southeast of Kodiak Island. Although this earthquake had a prominent aftershock sequence with many events recorded by the USGS network, only the location of the mainshock is presented in the catalog (see Gedney, 1978, for a more complete listing of the aftershocks). Nine earthquakes with codaduration magnitudes ranging from 2.3 to 3.9 were located southeast of the network in the vicinity of Cross Sound and Glacier Bay.

The contents of the Appendix may be obtained in forms amenable to computer input (punched cards or magnetic tape) by contacting the authors. 


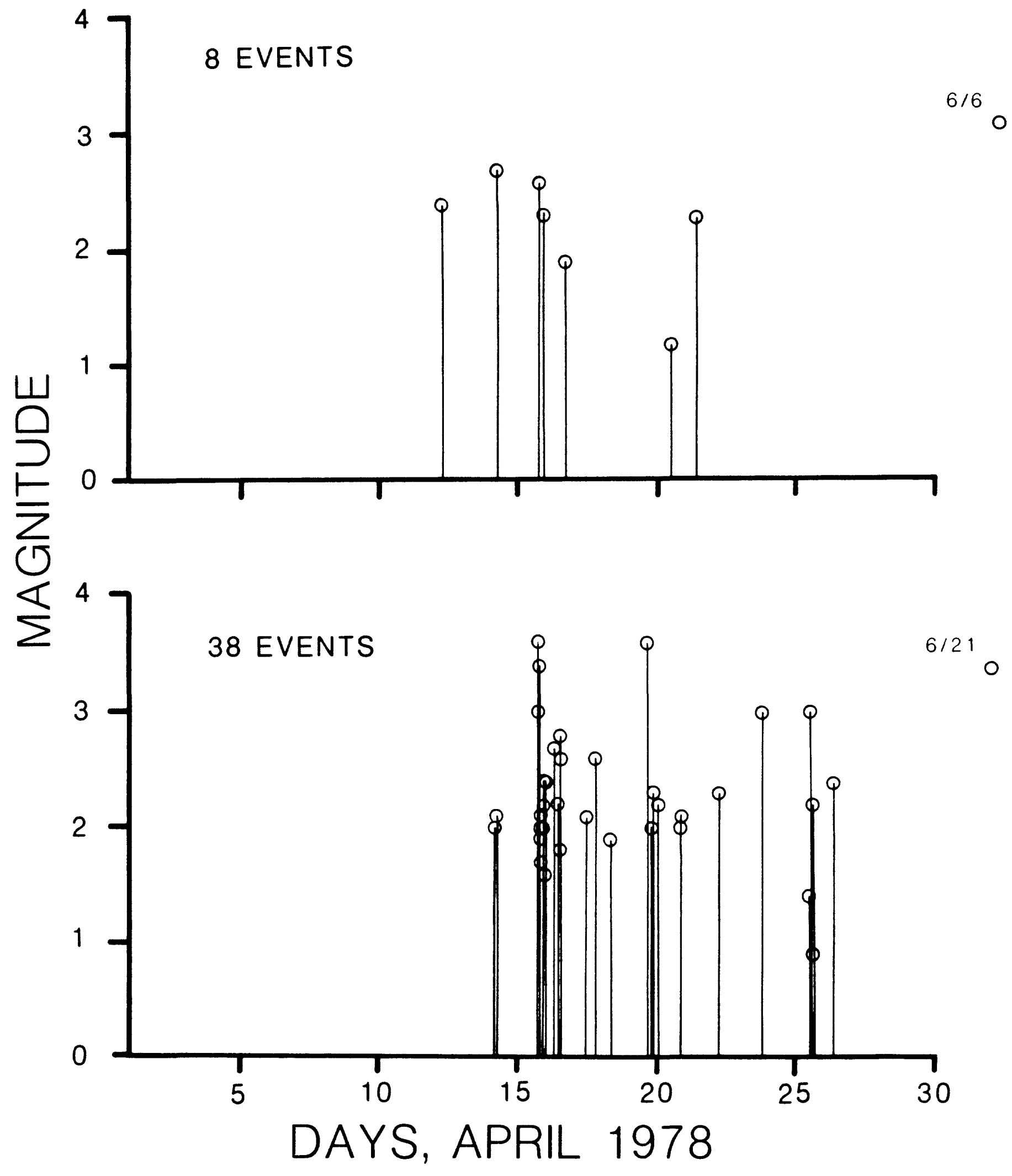

Figure 10. Magnitude versus time distribution of earthquakes for two clusters north of eastern portion of network (see text). The main cluster is plotted in the lower part of the figure. Dates and magnitudes for two events that occurred in June are indicated at right. 
We thank Robert Eppley, Wayne Jorgensen, and the entire staff of the NOAA Tsunami Warning Center for their assistance in maintaining our recording equipment in Palmer, Alaska, as well as making their seismic data available to us.

We also wish to thank Hans Pulpan of the Geophysical Institute of the University of Alaska for a cooperative operation of southern cook Inlet seismograph stations.

We are indebted to all of those who have spent time fabricating, installing, and maintaining the seismograph network in Alaska, particularly John Rogers. W. H. K. Lee was responsible for much of the work in developing the interactive digitizing-data processing system used in analyzing the data for this catalog.

Betty MCIntire and the staff of the USGS Anchorage office has been of great assistance in solving logistic problems, both in the field and in the office.

This catalog is patterned after those prepared for central California and we gratefully acknowledge Drs. W. H. K. Lee and R. L. Wesson for development of many of the procedures and techniques used herein.

This work was supported jointly by the U.S. Geological Survey and by the National Oceanic and Atmospheric Administration, under which a multi-year program responding to needs of petroleum development of the Alaskan continental shelf is managed by the Outer continental Shelf Environmental Assessment Program (OCSEAP) Office. 


\section{REFERENCES}

Eaton, J. P., O'Neil1, M. E., and Murdock, J. N., 1970, Aftershocks of the 1966 Parkfield-Cholame, California, earthquake: a detailed study: Bulletin of the Seismological Society of America, v. 60, p. 1151-1197.

Fogleman, K., Stephens, C., Lahr, J. C., Helton, S., and Allan, M., 1978, Catalog of earthquakes in southern Alaska, October-December 1977: U.S. Geological Survey Open-File Report 78-1097, 28 p.

Gedney, Larry, ed., 1978, Summary of Al askan Earthquakes, April, May, June 1978, Alaska Earthquake Analysis Center, Seismological Bulletin no. 4, Geophysical Institute, University of Alaska, $57 \mathrm{p}$.

Jacob, K. H., 1972, Global tectonic implications of anomalous seismic $P$ traveltimes from the nuclear explosion Longshot: Journal of Geophysical Research, v. 77, p. 2556-2573.

King, P. B., compiler, 1969, Tectonic Map of North America: U.S. Geological Survey, scale 1:5,000,000.

Lahr, J. C., 1975, Detailed seismic investigation of Pacific-North American plate interaction in southern Alaska: Ph.D. dissertation, Columbia University, $141 \mathrm{p}$.

Lahr, J. C., 1980, HYPOELLIPSE/MULTICS: A computer program for determining local earthquake hypocentral parameters, magnitude, and first motion pattern: U.S. Geological Survey Open-File Report 80-59, $59 \mathrm{p}$.

Lahr, J. C., Page, R. A., and Thomas, J. A., 1974, Catalog of earthquakes in southern Alaska, April-June 1972, U.S. Geological Survey Open-File Report, $35 \mathrm{p}$.

Lee, W. H. K., and Lahr, J. C., 1972, HYP07l: a computer program for determining hypocenter, magnitude, and first motion pattern of local earthquakes: U.S. Geological Survey Open-File Report, $100 \mathrm{p}$.

Lee, W. H. K., Bennett, R. E., and Meagher, K. L., 1972, A method of estimating magnitude of local earthquakes from signal duration: U.S. Geological Survey Open-File Report, $28 \mathrm{p}$.

Matumoto, T., and Page, R. A., 1969, Microaftershocks following the Alaska earthquake of 28 March 1964: determination of hypocenters and crustal velocities in the Kenai Peninsula-Prince William Sound area, in The Prince William Sound, Alaska, Earthquake of 1964 and Aftershocks, v. 2B and C, U.S. Coast and Geodetic Survey Publication 10-3, U.S. Government Printing Office, Washington, D.C., p. 157-173.

Meyers, H., 1976, A historical summary of earthquake epicenters in and near Alaska: NOAA Technical Memorandum EDS NGSDC-1, $57 p$.

Mitronovas, W., and Isacks, B. L., 1971, Seismic velocity anomalies in the upper mantle beneath the Tonga-Kermadec island arc: Journal of Geophysical Research, v. 76, p. 7154-7180.

Pelton, J. R., Astrue, M. C., Davidson, V. S., Lee, W. H. K., and Rogers, A. H., 1982, A computer-based sonic digitizing table for interactive earthquake locations: U.S. Geological Survey Open-File Report (in preparation).

Plafker, G., 1967, Geologic map of the Gulf of Alaska Tertiary Province, Alaska: U.S. Geological Survey Miscellaneous Investigations Map I-484, scale 1:500,000.

Richter, C. F., 1958, Elementary Seismology: W. H. Freeman and Co., San Francisco, 768 p. 
Rogers, J. A., Maslak, S., and Lahr, J. C., 1980, A seismic electronic system with automatic calibration and crystal reference: U.S. Geological Survey Open-File Report 80-324, 130p.

Stephens, C. D., Fogleman, K. A., Lahr, J. C., Helton, S. M., Cancilla, R. S., Tam, Roy, and Freiberg, J. A., 1980a, Catalog of earthquakes in southern Alaska, January-March, 1980: U.S. Geological Survey Open-File Report $80-1253,55 \mathrm{p}$.

Stephens, C. D., Lahr, J. C., Fogleman, K. A., Allan, M. A., and Helton, S. M., 1979, Catalog of earthquakes in southern Alaska, January-March 1978:

U.S. Geological Survey Open-File Report 79-718, 31p.

Stephens, C. D., Lahr, J. C., Fogleman, K. A., and Horner, R. B., 1980b, The St. Elias, Alaska, earthquake of 28 February 1979: regional recording of aftershocks and short term pre-earthquake seismicity:

Bulletin of the Seismological Society of America, v. 70, p. 1607-1633. 


\section{APPENDIX}

\section{Catalog of Earthquakes}

Earthquakes from southern Alaska are listed in chronological order. The following data are given for each event:

(1) Origin time in Universal Time (UT): date, hour (HR), minute (MN), and second (SEC). To convert to Alaska Standard Time (AST) subtract ten hours.

(2) Epicenter in degrees and minutes of north latitude (LAT $N$ ) and west longitude (LONG W).

(3) DEPTH, depth of focus in kilometers.

(4) MAG, duration magnitude (FMAG) of the earthquake, if available, otherwise amplitude magnitude (XMAG, indicated by "a").

(5) NP, number of $P$ arrivals used in locating earthquake.

(6) NS, number of $S$ arrivals used in locating earthquake.

(7) GAP, largest azimuthal separation in degrees between stations.

(8) D3, epicentral distance in kilometers to the third closest station to the epicenter.

(9) RMS, root-mean-square error in seconds of the traveltime residuals:

$$
R M S=\sqrt{\sum_{i}\left(R_{P_{i}}^{2}+R_{S_{i}}^{2}\right) /(N P+N S)}
$$

where $R_{p_{i}}$ and $R S_{j}$ are the observed minus the computed arrival times of $p$ - and $s$-waves respectively at the $i-t h$ station.

(10) ERH, largest horizontal deviation in kilometers from the hypocenter within the one-standard-deviation confidence ellipsoid. This quantity is a measure of the epicentral precision for an event. Values of ERH that exceed $25 \mathrm{~km}$ are tabulated as $25 \mathrm{~km}$.
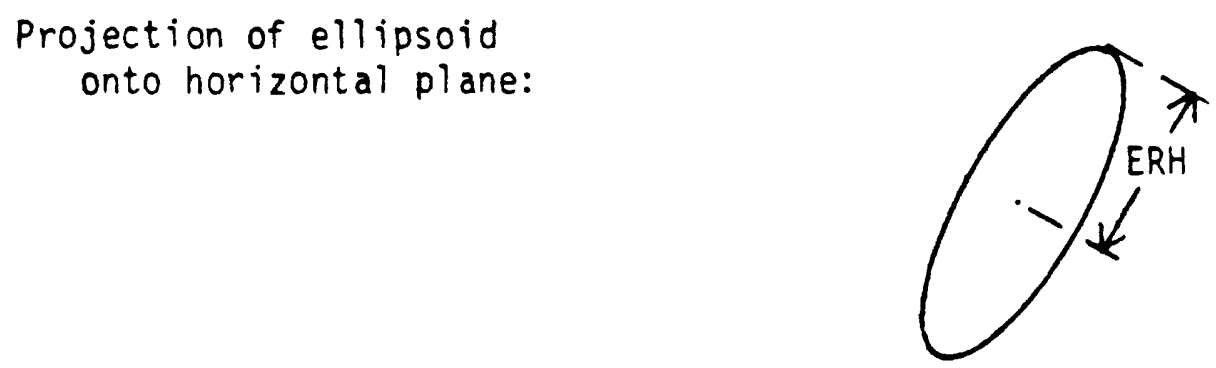
(11) ERZ, largest vertical deviation in kilometers from the hypocenter within the one-standard-deviation confidence ellipsoid. This quantity is a measure of the depth precision for an event. Values of ERZ that exceed $25 \mathrm{~km}$ are tabulated as $25 \mathrm{~km}$.

Projection of ellipsoid onto vertical plane:

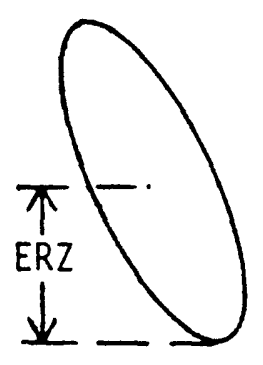

(12) Q, quality of the hypocenter. This index is a measure of the precision of the hypocenter (see section Analys is of Quality) and is calculated from ERH and ERZ as follows:

$$
\begin{array}{lll}
Q & \frac{E R H}{2.5} & \leq \frac{E R Z}{2.5} \\
A & \leq 5.0 & \leq 5.0 \\
B & \leq 10.0 & \leq 10.0 \\
C & >10.0 & >10.0
\end{array}
$$

(13) AZ1, DIP1, and SE1 are the azimuth in degrees (clockwise from north), dip in degrees, and standard error in.kilometers of the most nearly horizontal of the three principal axes of the one-standarddeviation error ellipsoid. Values of SEl that exceed $25 \mathrm{~km}$ are tabulated as $25 \mathrm{~km}$.

(14) AZ2, DIP2, and SE2 are defined as above, but correspond to the principal axis of intermediate dip.

(15) AZ3, DIP3, and SE3 are defined as above, buit correspond to the most nearly vertical principal axis. 


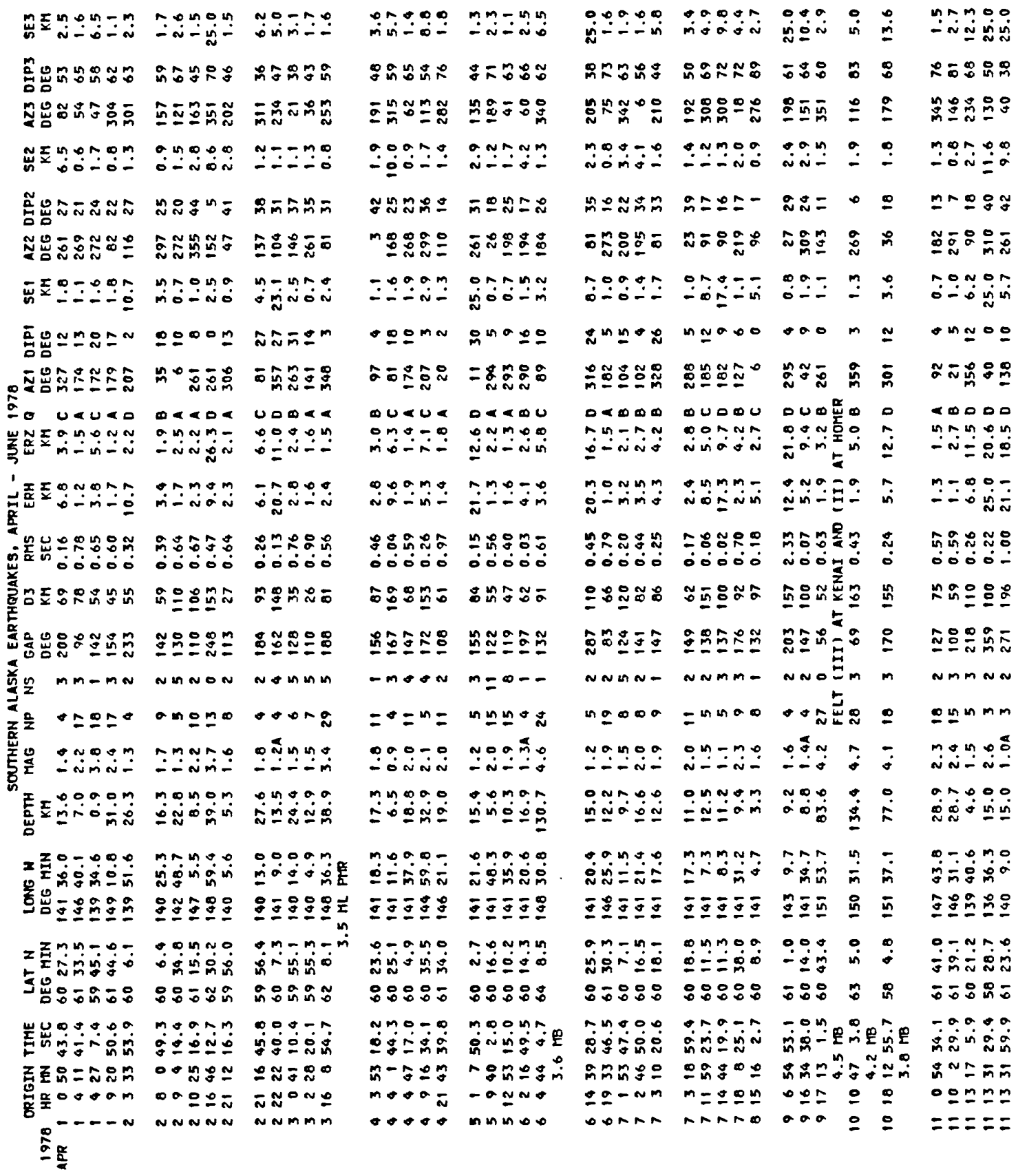




\begin{tabular}{|c|c|c|c|c|c|c|c|c|c|c|c|c|}
\hline 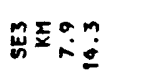 & $\dot{m}-\stackrel{\varphi}{-}$ & 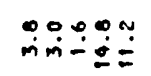 & 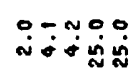 & $\dot{m}$ & 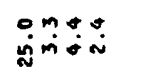 & 象: & $\stackrel{m}{m}=$ & 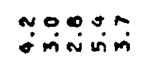 & 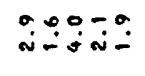 & $\dot{:}=\dot{m}$ & $\stackrel{00}{-\infty}$ & $\dot{m} \dot{m} \dot{0}: 0$ \\
\hline & ก: & 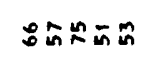 & 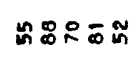 & $\theta$ & 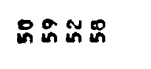 & กิ๊ & $\therefore$ & 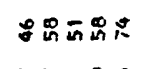 & 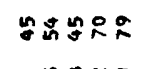 & 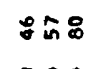 & $8:$ & 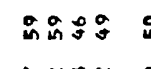 \\
\hline & ๕ & 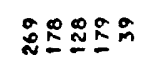 & 里距全路 & $\tilde{m}$ & 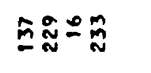 & $\approx \mathscr{p} \%$ & $\underline{m}$ & 的品是思 & m & $\frac{2 \pi}{N}$ & $\frac{0}{m}$ & $\tilde{F} \tilde{m} \tilde{m}$ \\
\hline 每 & $\ddot{\text { में }}$ & 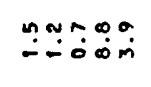 & 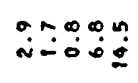 & $\dddot{-}$ & $\dot{m}=\mathfrak{\dot { m }}$ & 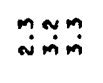 & $\stackrel{n}{i-}$ & 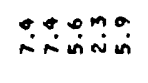 & ن & mo: & $\stackrel{m}{m} \dot{m}$ & 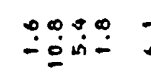 \\
\hline & $: \simeq \simeq$ & 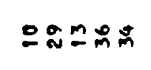 & $\ddot{m \sim ⿻ 口}$ & $\bullet$ & 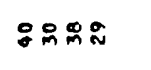 & $\simeq \simeq$ & $=\cong$ & 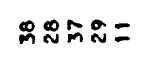 & ลิํํำ & 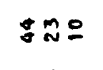 & $m=$ & 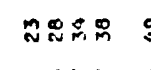 \\
\hline & in $\bar{N}$ i & 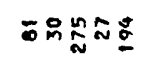 & 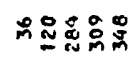 & $\bar{n}$ & 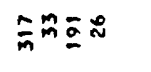 & $\alpha_{\alpha}^{\alpha} \alpha \hat{N}$ & 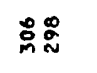 & 巨兌蓝ニ & હニミ゙ & 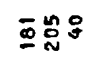 & : & 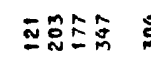 \\
\hline & $\stackrel{m}{\dot{0}=} \stackrel{0}{0}$ & 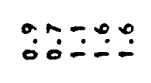 & 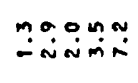 & $\because$ & : & 象㩆 & $\dot{b m}$ & نَّ & $\dddot{n} \dot{m} \dot{m} \dot{m}$ & भिज्ञ & $\stackrel{\sim}{\circ}$ & 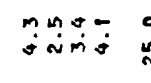 \\
\hline & & $n \simeq \infty \pm$ & OOMn & - & ORN N & & - $m$ & $\because=n=m=$ & $m m+m$ & $n \approx-$ & $\tilde{m}^{+}$ & 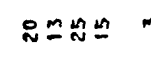 \\
\hline & $\underline{\tilde{n}}=\dot{\Phi}$ & 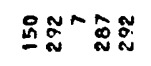 & 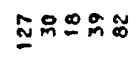 & $\overline{-}$ & 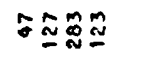 & 莡 స̃ & $\frac{n}{N} 2$ & 芯莒 N & 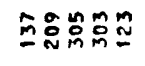 & 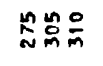 & $\stackrel{\circ}{=}$ & 赵总总总 \\
\hline & $0<\leqslant$ & 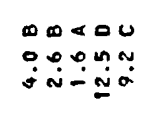 & 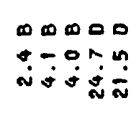 & $\begin{array}{c}\infty \\
\sim \\
\sim \\
m\end{array}$ & 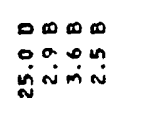 & 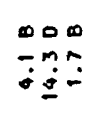 & 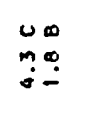 & 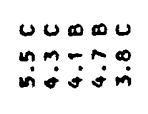 & 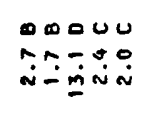 & $\begin{array}{l}\text { Uum } \\
0 \text { in n n } \\
\dot{0} \min \end{array}$ & $\begin{array}{l}\text { uo } \\
0: 0 \\
\text { mim }\end{array}$ & 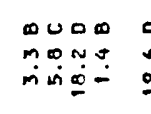 \\
\hline & $\frac{1}{\infty}=$ & 里品品 & 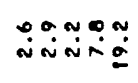 & 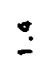 & 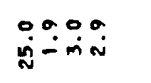 & $\stackrel{\circ}{\circ} \stackrel{m}{m}=\dot{m}$ & $\dot{\dot{0}} \dot{m}$ & 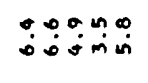 & 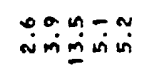 & omen: & in in & 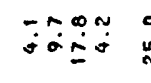 \\
\hline & 范 & ن & 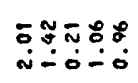 & $\begin{array}{l}: \\
: \\
:\end{array}$ & 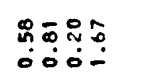 & 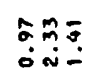 & $\underline{2}$ & & 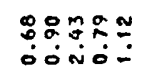 & 象等: & 号 & 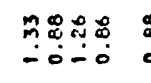 \\
\hline & $\therefore$ & 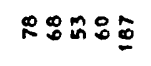 & 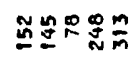 & $:$ & 果战蒀 & : & 星出 & 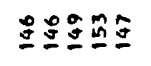 & 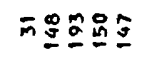 & 足里 & $\underline{\underline{n}}$ & 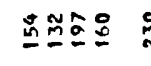 \\
\hline & $\tilde{m}$ & シ̄ズ嘿芯 & 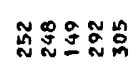 & $\stackrel{\infty}{\sim}$ & 总星出出 & 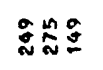 & 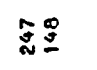 & 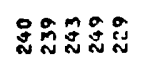 & 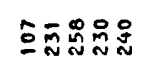 & 品亏 & 旁筩 & 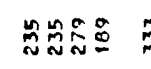 \\
\hline & \pm & DMNOA & 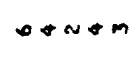 & - & minsm & onn & $\mathrm{mm}$ & 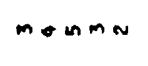 & $-n+n$ & ams & $\mathrm{mm}$ & Sman \\
\hline$\approx \approx-\pi$ & $\bar{N}$ & 므뭉 & อN- $\simeq$ & $m$ & $m \pm N$ & & $n \tilde{N}$ & mannom & $\therefore:=M r$ & $\operatorname{nos} a$ & no & $\simeq \min \bar{N}$ \\
\hline$\dot{m} \dot{m}$ & $\ddot{i m} \bar{i}$ & 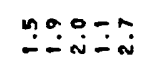 & 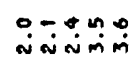 & $\hat{m}$ & 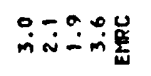 & : & E̊: & 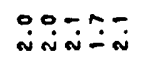 & 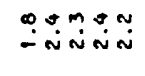 & 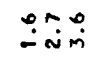 & 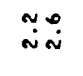 & 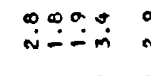 \\
\hline & $\ddot{\tilde{a}} \ddot{\ddot{y}} \overrightarrow{\dot{\phi}}$ & 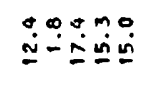 & 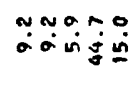 & $\tilde{\tilde{~}}$ & 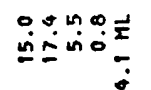 & & & 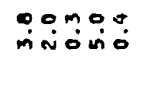 & 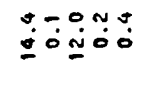 & $\ddot{\circ}$ & $\stackrel{\circ}{\circ}$ & 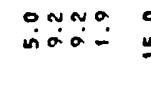 \\
\hline 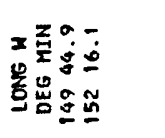 & 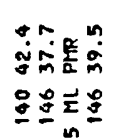 & 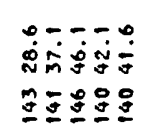 & 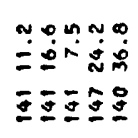 & $\begin{array}{l}\dot{\Phi} \\
\dot{\bar{n}}\end{array}$ & 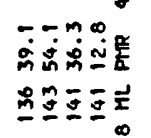 & 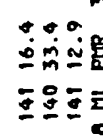 & 年 & 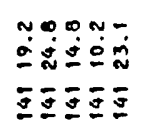 & 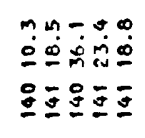 & 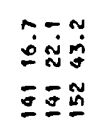 & 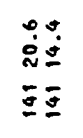 & 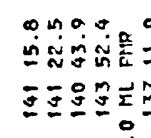 \\
\hline 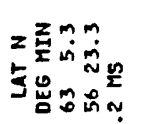 & 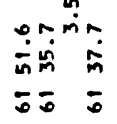 & 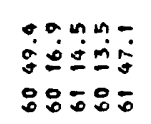 & 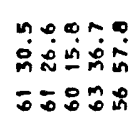 & $\begin{array}{l}\overline{\dot{N}} \\
:\end{array}$ & 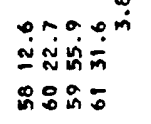 & 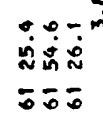 & 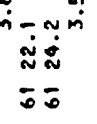 & 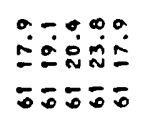 & 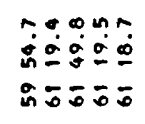 & 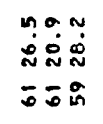 & 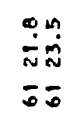 & 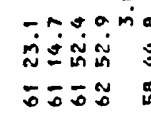 \\
\hline & 家 & 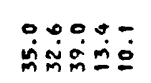 & 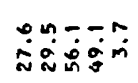 & & 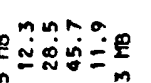 & 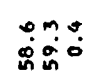 & & 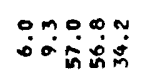 & & & & 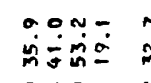 \\
\hline & 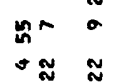 & 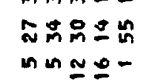 & 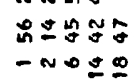 & & 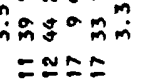 & $\begin{array}{l}\text { 的的品 } \\
=\approx=\end{array}$ & $\because$ & 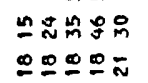 & $\begin{array}{l}8 \mathbb{N} N \bar{N} \\
\bar{N} \bar{N} N \mathbb{N}\end{array}$ & 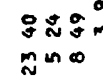 & $\begin{array}{l}\dot{m}=n \\
0=n \\
0=\end{array}$ & 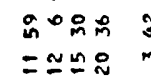 \\
\hline$:$ & & $m m m \underline{m}$ & ヒேさロさ & - & $\underline{m} \simeq \underline{m}$ & $\ldots-$ & -- & 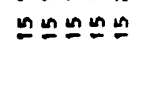 & 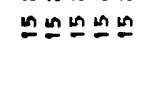 & $\because \simeq$ & $\simeq 2$ & உㅗㅇ \\
\hline
\end{tabular}




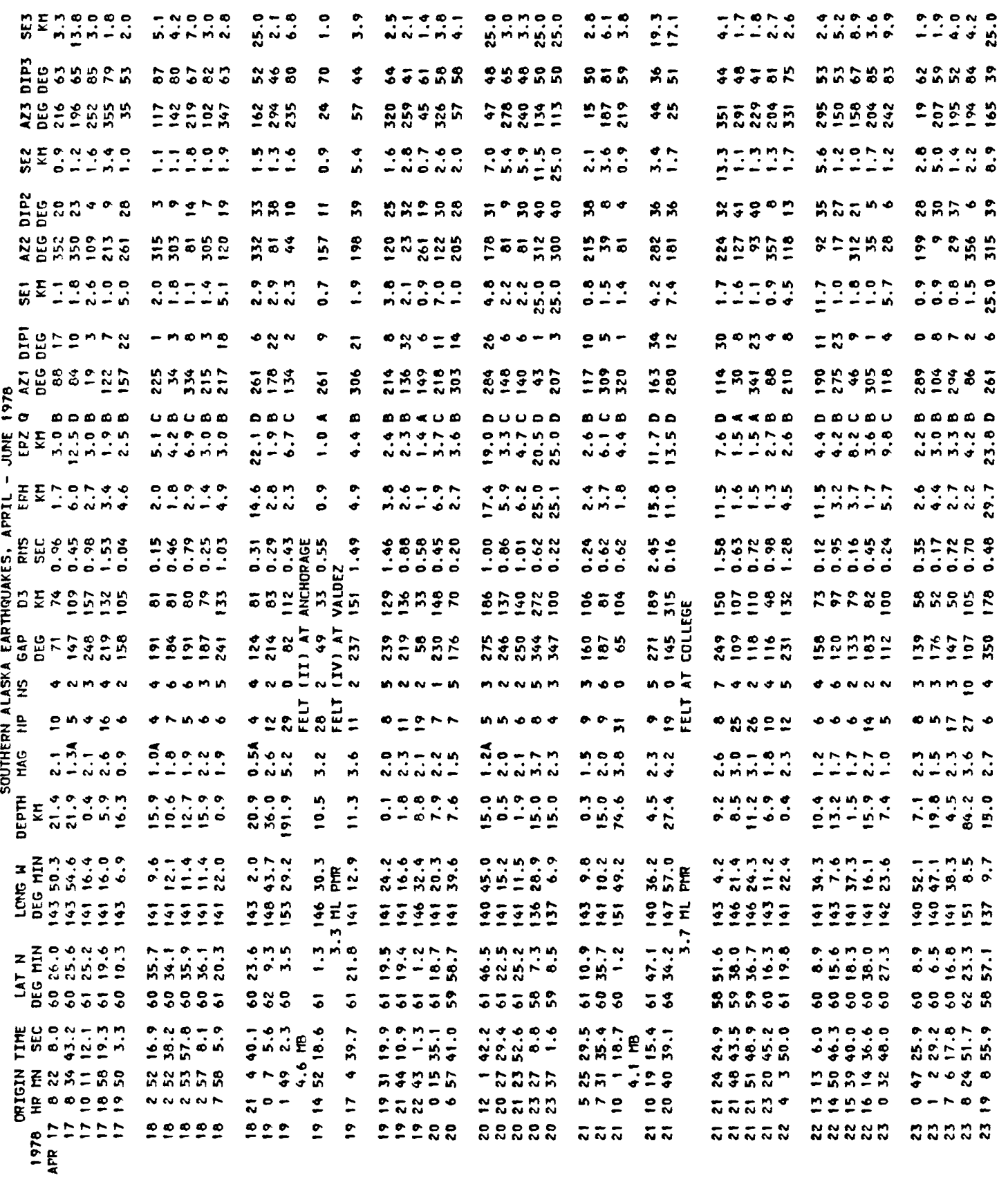




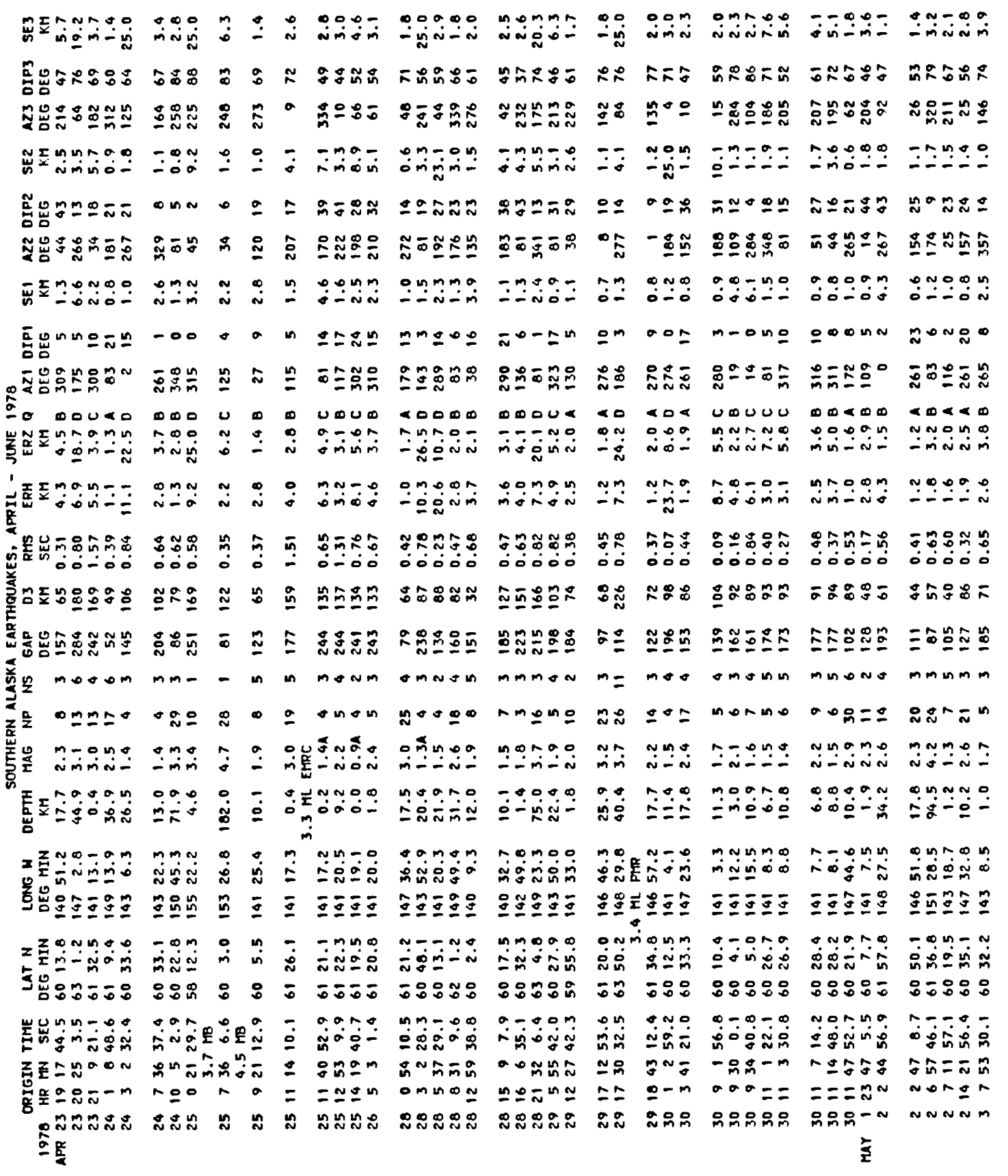




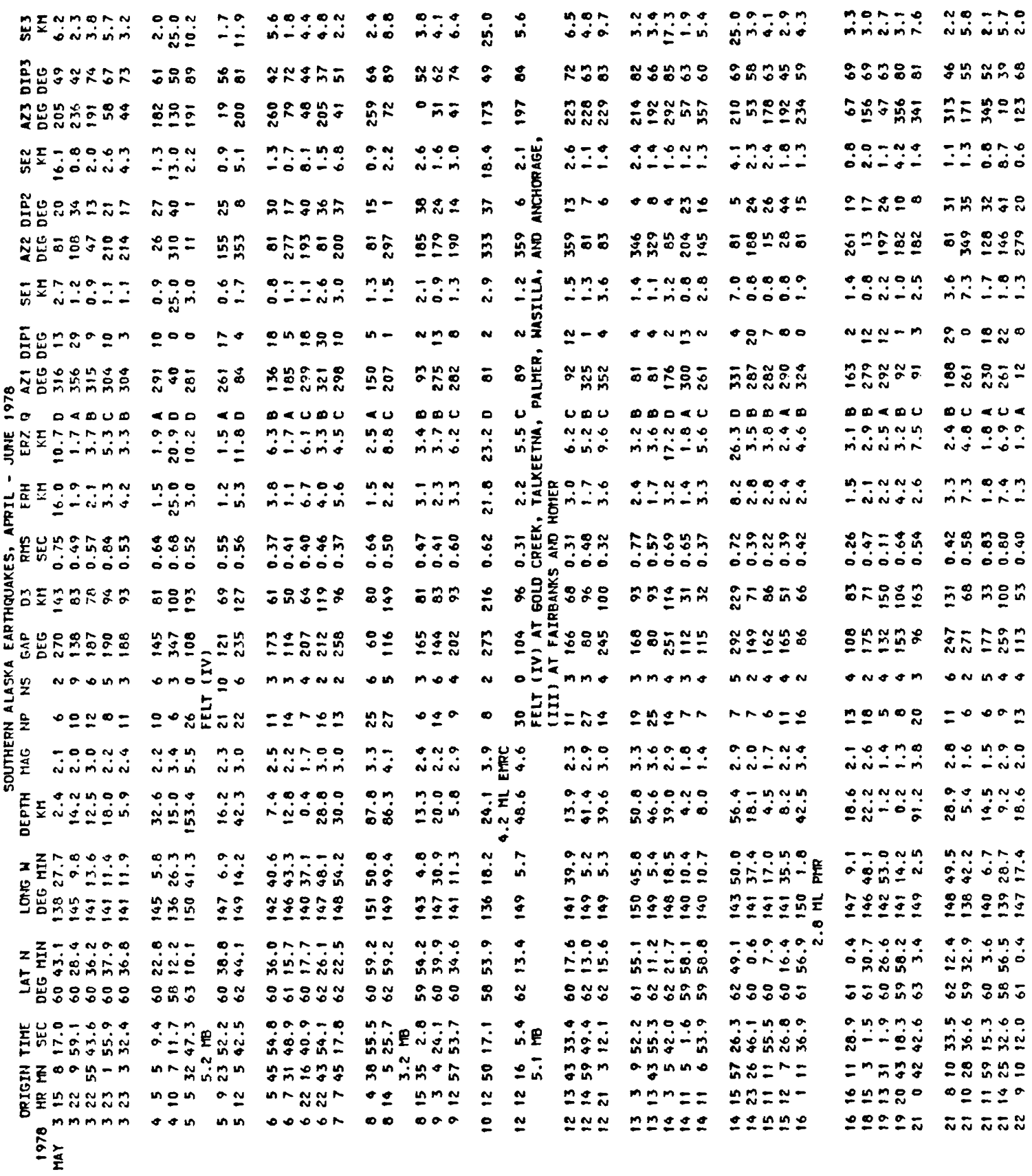




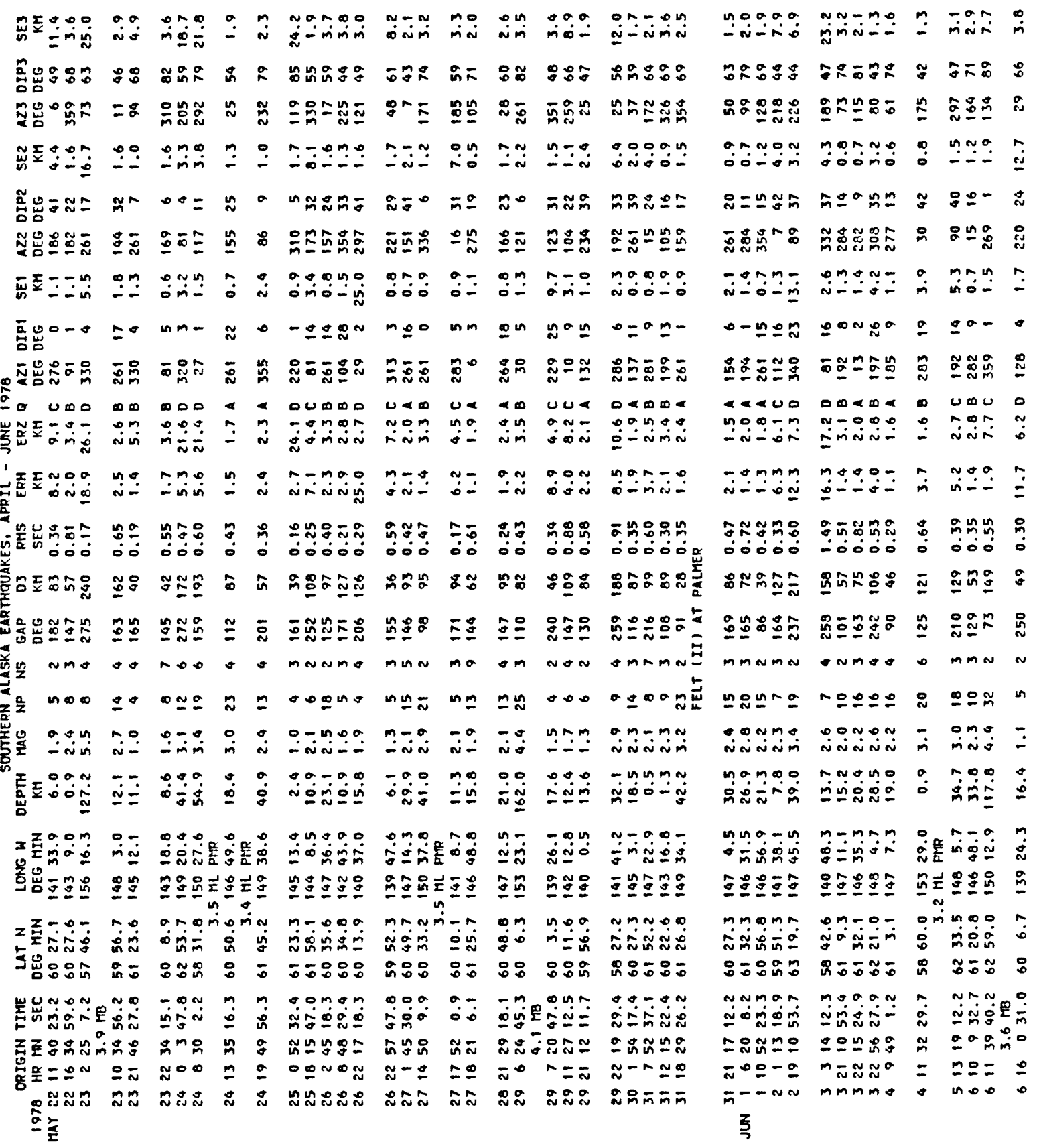




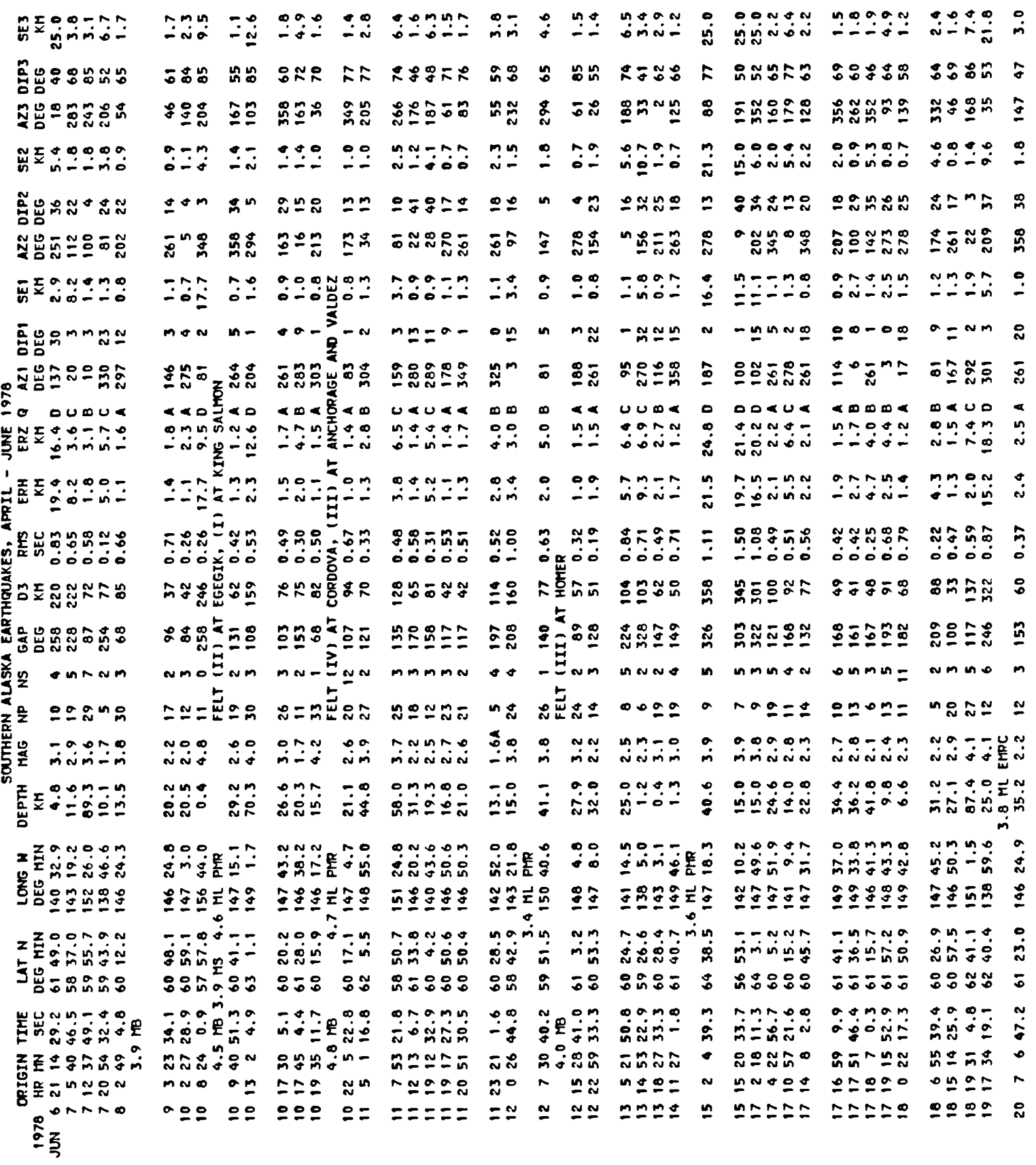




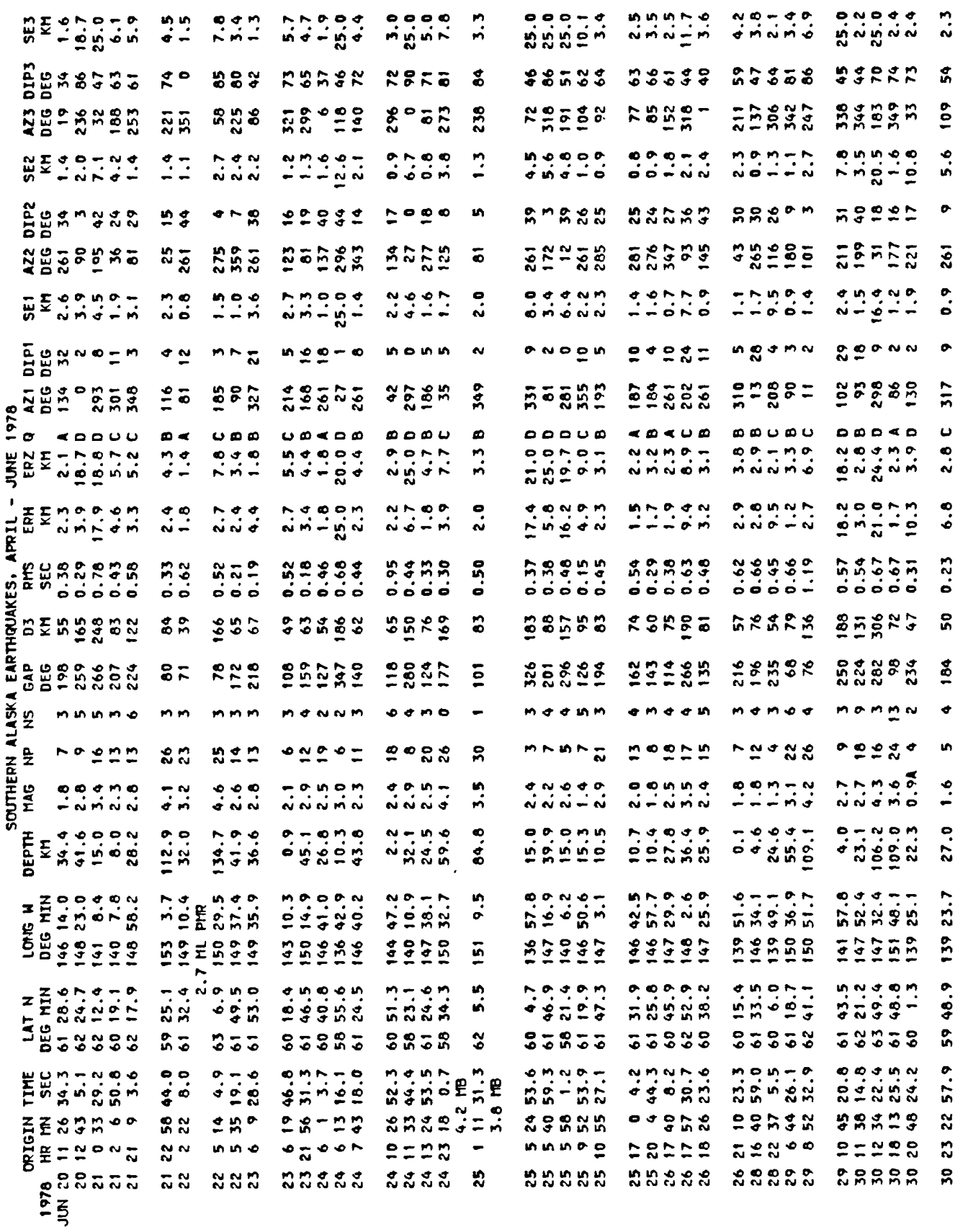

